\title{
Tension-Bearing Couples (TBC), Part III*: Developing Fastener Maximum Load Correction Factors Charts
}

\author{
Hatem H. Daken ${ }^{\dagger}$ and M. Kamal Shoukry ${ }^{\ddagger}$
}

\begin{abstract}
A study was conducted to determine the effect of fasteners/fitting modulus of elasticity ratio on the fastener maximum load correction factors obtained from realistic FEM models and the proposed enhanced analysis approach. This study entails 392 FEM and analytical model runs. Statistical analyses demonstrate that the fastener maximum load correction factors curves reach constant plateaus at a fasteners/fitting modulus of elasticity ratio of approximately 1.00. The angle factor curve, on the other hand, is increasing with increasing values of the fasteners/fitting modulus of elasticity ratio. The proposed enhanced analysis approach, together with the fastener maximum load correction factors curves of this study, can yield results that are comparable with those obtained from realistic FEM models.
\end{abstract}

Keywords: Tension-Bearing Couple, Tensile-Loaded Fasteners, Bolted Joints, Fastener Joints, Finite Element Method, Finite Element Analysis, Finite Element Modeling

\section{Introduction}

A new analysis approach to compute fastener tensile loads in tension-bearing couples (TBC) loaded with out-of-plane bending moments was introduced in Reference 1. Finite Element validation of this analysis approach ${ }^{1}$, using idealized FEM models that preclude flexural and shear deformations in the fitting, is introduced in Reference 2. Validation of the proposed enhanced analysis approach ${ }^{2}$, using realistic FEM models that permit flexural and shear deformations in the fitting, is introduced in Reference 3. Results of the realistic FEM models exhibit significant differences from the results of proposed enhanced analysis approach ${ }^{3}$.

This article discusses the study that was conducted to develop fastener maximum load correction factors charts to be used in conjunction with the proposed enhanced analysis approach $^{2,3}$. Together, they yield fastener maximum loads that are conservative and equal to, or higher than, the fastener maximum loads predicted by the realistic FEM models. This study entails 56 realistic FEM models based on the seven (7) joints used in Reference 3. Each of these joints has eight (8) different material combinations for the fasteners and fitting. Each model and material combination was run for seven (7) values of the applied out-of-plane bending moment angle with respect to the local $x$-axis. These angle values entail: $0^{\circ}, 15^{\circ}$, $30^{\circ}, 45^{\circ}, 60^{\circ}, 75^{\circ}$, and $90^{\circ}$. Details of the realistic FEM models and their material combinations are depicted in Table 1 . The total processing time of these 392 (56x7) realistic FEM model runs is approximately 506 hours plus 196 hours for data collection and model setting.

\footnotetext{
* Refer to the other two parts in this volume

${ }^{\dagger}$ Ph.D., Senior Structural Analysis Scientist/Engineer, Boeing Commercial Airplanes, The Boeing Company, Seattle, WA, USA, hatemdaken@aol.com

$\ddagger$ Ph.D., Professor of Design and Production Engineering, German University, Cairo, Egypt
} 


\section{Finite Element Modeling}

Autodesk $^{\mathrm{TM}}$ Algor $^{\mathrm{TM}}$ Simulation 2010 was used to construct the realistic FEM models under investigation. All components of these models (fitting, fasteners, and substrate/base) are meshed using isotropic 8-node brick elements with compatibility enforced. An approximate absolute mesh size of 0.065 ” is used for all components. Surface contact pairs are established between the upper fastener heads and the upper surface/plane of the fitting, the lower surface/plane of the fitting and the upper surface/plane of the substrate/base, and the lower surface/plane of the substrate/base and the lower fastener heads. The details of these realistic finite element models are described and depicted in Reference 3. Specifications of the fitting and fastener materials used are detailed in Table 2.

Table 1: Fasteners/Fitting Material Combinations and Number of Model Runs

\begin{tabular}{|c|c|c|c|c|c|}
\hline & & \multicolumn{4}{|c|}{ Fitting } \\
\hline & & Fictitious & Aluminum & Titanium & Steel \\
\hline \multirow{3}{*}{ 总 } & Aluminum & & & $\begin{array}{c}49 \\
(7 \times 7)^{*}\end{array}$ & $\begin{array}{c}49 \\
(7 \times 7)^{*}\end{array}$ \\
\hline & Titanium & $\begin{array}{c}49 \\
(7 \times 7)^{*}\end{array}$ & $\begin{array}{c}49 \\
(7 \times 7)^{*}\end{array}$ & $\begin{array}{c}49 \\
(7 \times 7)^{*}\end{array}$ & $\begin{array}{c}49 \\
(7 \times 7) *\end{array}$ \\
\hline & Steel & & $\begin{array}{c}49 \\
(7 \times 7)^{*}\end{array}$ & $\begin{array}{c}49 \\
(7 \times 7)^{*}\end{array}$ & \\
\hline
\end{tabular}

Table 2: Specifications of the Materials Used for the Fitting and Fasteners

\begin{tabular}{|c|c|c|c|}
\hline Component & Material & Material Specification & $\begin{array}{c}\text { Modulus of } \\
\text { Elasticity [psi] }\end{array}$ \\
\hline $\begin{array}{c}\text { Fitting \& } \\
\text { Substrate/Base }\end{array}$ & Fictitious & $\begin{array}{l}\text { Fictitious material based on AISI } 4130 \\
\text { low-alloy Steel per AMS } 6350\end{array}$ & $29.0 \mathrm{E}+12$ \\
\hline \multirow{3}{*}{ : } & Aluminum & $\begin{array}{l}\text { 7050-T74 Aluminum Die Forging per } \\
\text { AMS 4107, MIL-A-22771 }\end{array}$ & $\begin{array}{l}10.2 \mathrm{E}+06 \\
10.7 \mathrm{E}+06\end{array}$ \\
\hline & Titanium & $\begin{array}{l}\text { Ti-6Al-4V Titanium Annealed Plate per } \\
\text { MIL-T-9046 AB-1, and AMS } 4911\end{array}$ & $16.0 \mathrm{E}+06$ \\
\hline & Steel & $\begin{array}{l}4140 \text { 125-145 Forging Steel per MIL-S- } \\
\text { 5626, AMS } 6382\end{array}$ & $29.0 \mathrm{E}+06$ \\
\hline \multirow{3}{*}{ 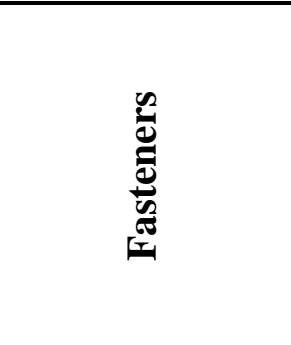 } & Aluminum & $\begin{array}{l}\text { 2024-T4 Aluminum Bar per AMS } 4120 \\
\text { and AMS-QQ-A-225/6 }\end{array}$ & $10.5 \mathrm{E}+06$ \\
\hline & Titanium & $\begin{array}{l}\text { Ti-6Al-4V Solution Treated and Aged } \\
\text { Titanium Bar per MIL-T-9047, AMS } \\
\text { 4965, AMS-T-9047, and AMS 6930 }\end{array}$ & $16.9 \mathrm{E}+06$ \\
\hline & Steel & $\begin{array}{l}4140 \text { 125-145 Steel Bar per MIL-S-5626, } \\
\text { AMS } 6382\end{array}$ & $29.0 \mathrm{E}+06$ \\
\hline
\end{tabular}

The fasteners/fitting modulus of elasticity ratios are computed using the modulus of elasticity values listed in Table 2. The fictitious material was used also for the substrate/base of all realistic FEM models. Table 3 summarizes all the fasteners/fitting modulus of elasticity ratios investigated in this study. These ratios represent every possible material combination from a structural engineering perspective. Fastener maximum load correction factors for other ratios can be interpolated or extrapolated using the results of current ratios. 
Table 3: Fasteners/Fitting Modulus of Elasticity Ratios

\begin{tabular}{|c|c|c|c|c|c|}
\hline & & \multicolumn{4}{|c|}{ Fitting } \\
\hline & & Fictitious & Aluminum & Titanium & Steel \\
\hline \multirow{3}{*}{ 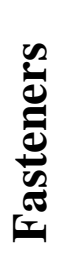 } & Aluminum & & & 0.656250 & 0.362069 \\
\hline & Titanium & 0.000001 & $1.495327 *$ & 1.056250 & 0.582759 \\
\hline & Steel & & 2.843138 & 1.812500 & \\
\hline
\end{tabular}

\section{Results and Discussions}

The fastener maximum load correction factors plots are depicted in Figure 1 through Figure 8. A fastener maximum load correction factor is the ratio between the prediction of a realistic FEM model for a fastener maximum load and the prediction of the proposed enhanced analysis approach for it. Each of these plots, with the exception of that for titanium fasteners and fictitious material fitting, has an upper bound for the fastener maximum load correction factors. The upper bound can be computed for any fasteners/fitting material combination and value of the applied out-of-plane bending moment angle with respect to the local $\mathrm{x}$-axis using the following expression. The formula depicted on each of these figures is a simplified version.

$$
\operatorname{FMLCF}(p, \alpha)=\operatorname{FMLCF}(p)-\operatorname{AngFac} \cdot \sin (2 \cdot \alpha)
$$

where:

$\operatorname{FMLCF}(p, \alpha)$

Fastener maximum load correction factor as function of the angle of applied out-of-plane bending moment with respect to the local $\mathrm{x}$-axis and selected confidence level

FMLCF(p) Fastener maximum load correction factor as of function of selected confidence level

AngFac

$\alpha$ Factor to account for the angle of the applied out-of-plane bending moment vector with respect to the local $\mathrm{x}$-axis Angle of applied out-of-plane bending moment with respect to the local $\mathrm{x}$-axis

StatSoft ${ }^{\circledR}$, s STATISTICA 9.0.231.9 was utilized to create normal probability plots for the fastener maximum load correction factors. Each of these plots entails correction factors for all joints and applied out-of-plane bending moment angles for a given fasteners/fitting material combination. Resulting probability plots are depicted in Figure 9 through Figure 16. The abscissa of each of these plots represents observed values of fastener maximum load correction factors and the ordinate represents expected normal values, expressed in terms of a normal distribution's standard deviation multiplier. Observed values of fastener maximum load correction factors were obtained from the realistic FEM models and proposed enhanced analysis approach runs. 
STATISTICA was also used to fit a standard normal distribution to the observed fastener maximum load correction factors data of each of the fasteners/fitting material combinations. This statistical analysis entails correction factors for all joints and applied out-of-plane bending moment angles for a given fasteners/fitting material combination. An additional outcome of this analysis is the observed and expected probability and cumulative probability for the fastener maximum load correction factors.

As part of the above statistical analysis, STATISTICA performed a chi-square test ${ }^{4}$ to evaluate the goodness of fit of the fastener maximum load correction factors to a standard normal distribution. Based on the p-values obtained, none of the null hypotheses can be rejected. This simply means that the difference between expected and observed values is due to mere chance or random error. These results are illustrated in Table 4 and Table 5 below.

Table 4: Results of the $\chi^{2}$ Analyses

\begin{tabular}{|c|c|c|c|c|c|c|c|}
\hline $\begin{array}{c}\text { Material } \\
\text { Combination }\end{array}$ & $\begin{array}{c}\text { Modulus } \\
\text { of } \\
\text { Elasticity } \\
\text { Ratio }\end{array}$ & Mean & Variance & $\chi^{\mathbf{2}}$ & DOF & $\begin{array}{c}\mathbf{p} \\
\text { Value }\end{array}$ & $\begin{array}{c}\text { Can Reject } \\
\text { Null } \\
\text { Hypothesis? }\end{array}$ \\
\hline \hline TF & 0.0000 & 0.978373 & 0.002699 & 1.559180 & 3 & 0.66868 & NO \\
\hline AS & 0.3621 & 1.950424 & 0.361029 & 0.484700 & 3 & 0.92224 & NO \\
\hline TS & 0.5828 & 2.004325 & 0.392798 & 0.55204 & 3 & 0.90732 & NO \\
\hline AT & 0.6563 & 2.016000 & 0.400324 & 0.803530 & 3 & 0.84862 & NO \\
\hline TT & 1.0563 & 2.041159 & 0.422400 & 1.505400 & 3 & 0.68102 & NO \\
\hline TA & 1.4953 & 2.065630 & 0.414040 & 1.048170 & 3 & 0.78960 & NO \\
\hline ST & 1.8125 & 2.055205 & 0.432974 & 1.185240 & 3 & 0.75655 & NO \\
\hline SA & 2.8431 & 2.041898 & 0.426272 & 2.133870 & 3 & 0.54509 & NO \\
\hline
\end{tabular}

where:

$\begin{array}{ll}\text { TF } & \text { Titanium fasteners and fictitious material fitting } \\ \text { AS } & \text { Aluminum fasteners and steel fitting } \\ \text { TS } & \text { Titanium fasteners and steel fitting } \\ \text { AT } & \text { Aluminum fasteners and titanium fitting } \\ \text { TT } & \text { Titanium fasteners and titanium fitting } \\ \text { TA } & \text { Titanium fasteners and aluminum fitting } \\ \text { ST } & \text { Steel fasteners and titanium fitting } \\ \text { SA } & \text { Steel fasteners and aluminum fitting }\end{array}$

Expected probability and cumulative probability for the fastener maximum load correction factors, resulting from fitting a standard normal distribution to the fastener maximum load correction factors data of each of the fasteners/fitting material combinations, were used to construct expected probability and cumulative probability plots for this material combination. These plots, together with observed probability and cumulative probability, are depicted in Figure 17 through Figure 24.

Figure 25 is the summary of all data generated by this study. All fastener maximum load correction factors curves reach constant plateaus at a fasteners/fitting modulus of elasticity ratio of approximately 1.00 . To compute fastener maximum load correction factor for a given fasteners/fitting material combination use the following steps: 1) compute the modulus of elasticity ratio of the fasteners/fitting material combination; 2) locate this value on the abscissa of Figure 25 and construct a vertical line at it; 3) choose a confidence level and find 
the point of intersection of the vertical line with the fastener maximum load correction factors curve corresponding to chosen confidence level, interpolate between curves for other levels of confidence not included in Figure 25; 4) draw a horizontal line at this point of intersection and find its point of intersection with the left ordinate; 5) read the FMLCF(p) value from the left ordinate; 6) find the point of intersection of this vertical line with the angle factor curve; 7) draw a horizontal line at this point and find its point of intersection with the right ordinate; 8) read the AngFac value from the right ordinate; 9) compute $\operatorname{FMLCF}(\mathrm{p}, \alpha)$ using equation $1 ; 10)$ apply this factor to the fastener tensile loads, computed with the proposed enhanced analysis approach, at the joint's periphery only.

Table 5: Results of Fitting Normal Probability Plots to Fastener Maximum Load Correction Factors

\begin{tabular}{|c|c|c|c|c|c|c|c|}
\hline $\begin{array}{c}\text { Material } \\
\text { Combination }\end{array}$ & $\begin{array}{c}\text { Max. } \\
\text { Observed }\end{array}$ & $\begin{array}{c}\text { Max. } \\
\text { Expected }\end{array}$ & $\begin{array}{c}\text { Histogram } \\
\text { Categories }\end{array}$ & $\begin{array}{c}\text { Lower } \\
\text { Limit }\end{array}$ & $\begin{array}{c}\text { Upper } \\
\text { Limit }\end{array}$ & $\begin{array}{c}\text { Angle } \\
\text { Factor }\end{array}$ & $\begin{array}{c}\text { Coefficient } \\
\text { of } \\
\text { Variation }\end{array}$ \\
\hline \hline TF & 1.086109 & 1.119990 & 17 & 0.82 & 1.12 & 0.00 & $5.31 \%$ \\
\hline AS & 3.069767 & 3.400000 & 10 & 0.60 & 3.40 & 0.20 & $30.81 \%$ \\
\hline TS & 3.229002 & 3.600000 & 10 & 0.60 & 3.60 & 0.35 & $31.27 \%$ \\
\hline AT & 3.262869 & 3.600000 & 10 & 0.60 & 3.60 & 0.40 & $31.38 \%$ \\
\hline TT & 3.375743 & 3.800000 & 11 & 0.60 & 3.80 & 0.55 & $31.84 \%$ \\
\hline TA & 3.446003 & 3.800000 & 11 & 0.60 & 3.80 & 0.70 & $31.15 \%$ \\
\hline ST & 3.456797 & 3.800000 & 11 & 0.60 & 3.80 & 0.75 & $32.02 \%$ \\
\hline SA & 3.461427 & 3.800000 & 10 & 0.60 & 3.80 & 0.80 & $31.97 \%$ \\
\hline
\end{tabular}

\section{Conclusions}

Based on the statistical analyses performed on the fastener maximum load correction factors we can make the following conclusions. These conclusions, however, are valid only for joints with aspect ratios ranging from 0.538 to 9.75:

a. The upper bound of the fastener maximum load correction factors for a given fasteners/fitting material combination can be represented by a mathematical expression composed of: 1) fastener maximum load correction factor for a given fasteners/fitting modulus of elasticity ratio and $100 \%$ confidence level; 2) angle factor that accounts for the angle of applied out-of-plane bending moment; and 3) the angle of applied out-ofplane bending moment with respect to local x-axis.

b. The fastener maximum load correction factors curves achieve constant plateaus at a fasteners/fitting modulus of elasticity ratio of approximately 1.0 for all confidence levels.

c. The Angle Factor increases with increasing fasteners/fitting modulus of elasticity ratio.

d. The proposed enhanced analysis approach, together with the curves of Figure 25, can yield fastener maximum loads that are comparable to those obtained from realistic FEM models. 


\section{Acknowledgement}

The authors wish to acknowledge with sincere thanks the help and cooperation of Mr. Edward Simmons and Mr. Rajesh Radhakrishnan of Autodesk Inc. Mr. Simmons helped us to acquire the Algor software package at an appealing discounted price and Mr. Radhakrishnan provided us with technical support, help, and guidance throughout the finite element analysis phase of this effort. Without their unfailing assistance and support the completion of this work was highly doubtful.

\section{References}

[1] Daken, Hatem H., "Tension-Bearing Couples (TBC): An Analysis Approach for Fastener Joints Loaded By Out-Of-Plane Forces and Compound Bending Moments," 13th International Conference on Aerospace Sciences \& Aviation Technology, ASAT13, May $26-28,2009$

[2] Daken, Hatem H. and Shoukry, M. Kamal, “Tension-Bearing Couples (TBC), Part I: FEM Validation of Proposed Analysis Approach, Approach Enhancement, Results Comparisons and Evaluation,” 14th International Conference on Aerospace Sciences \& Aviation Technology, ASAT- 14, May 24 - 24, 2011

[3] Daken, Hatem H. and Shoukry, M. Kamal, "Tension-Bearing Couples (TBC), Part II: Adding Realism to the FEM Validation of Proposed Analysis Approach," 14th International Conference on Aerospace Sciences \& Aviation Technology, ASAT- 14, May 24 - 24, 2011

[4] Maben, Anne F., "CHI-SQUARE TEST - Adapted by from "Statistics for the Social Sciences" by Vicki Sharp,” http://www.enviroliteracy.org/pdf/materials/1210.pdf 


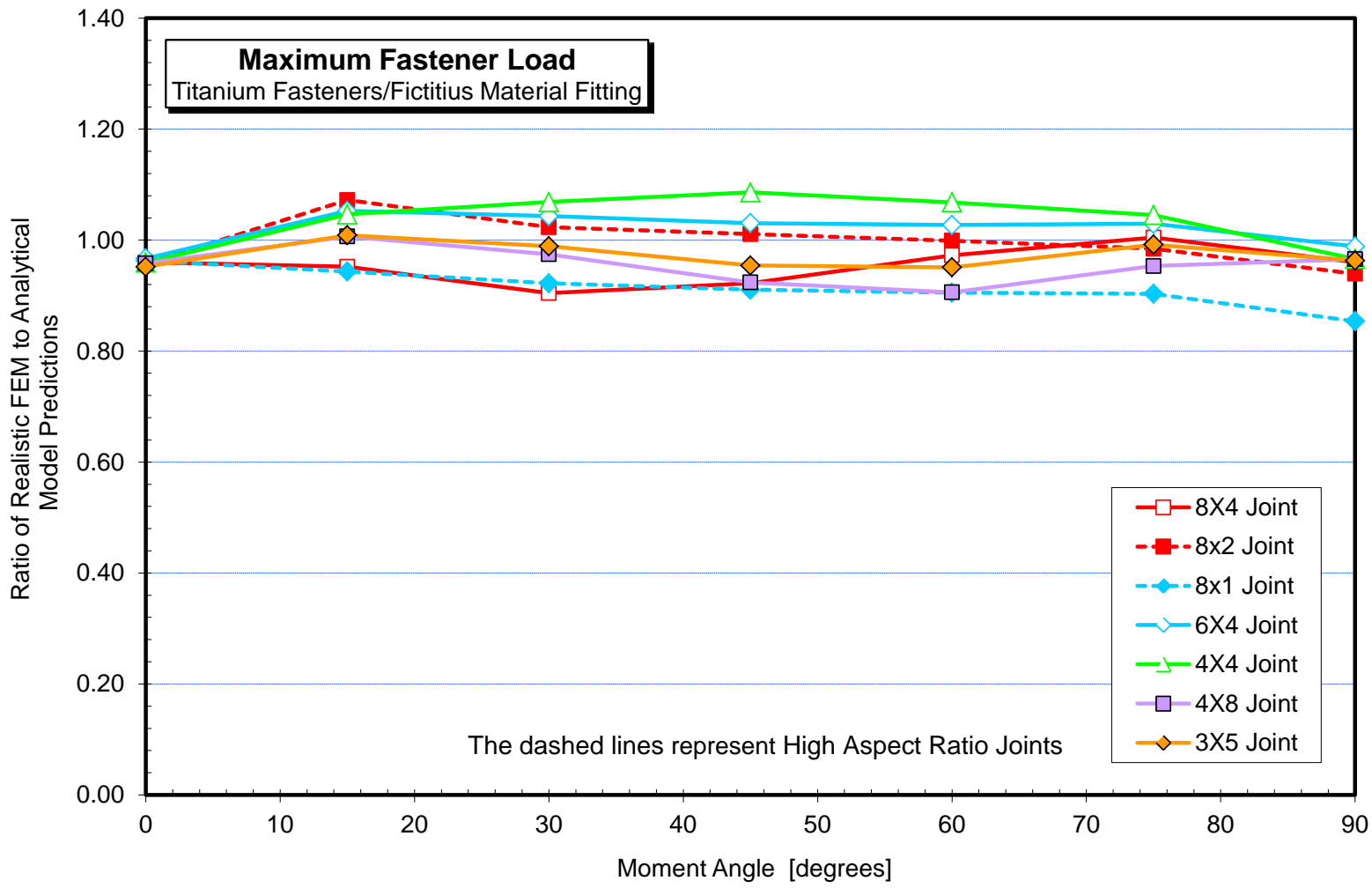

Figure 1: Fastener Maximum Load Correction Factor Plots for Titanium Fasteners and Fictitious Material Fitting

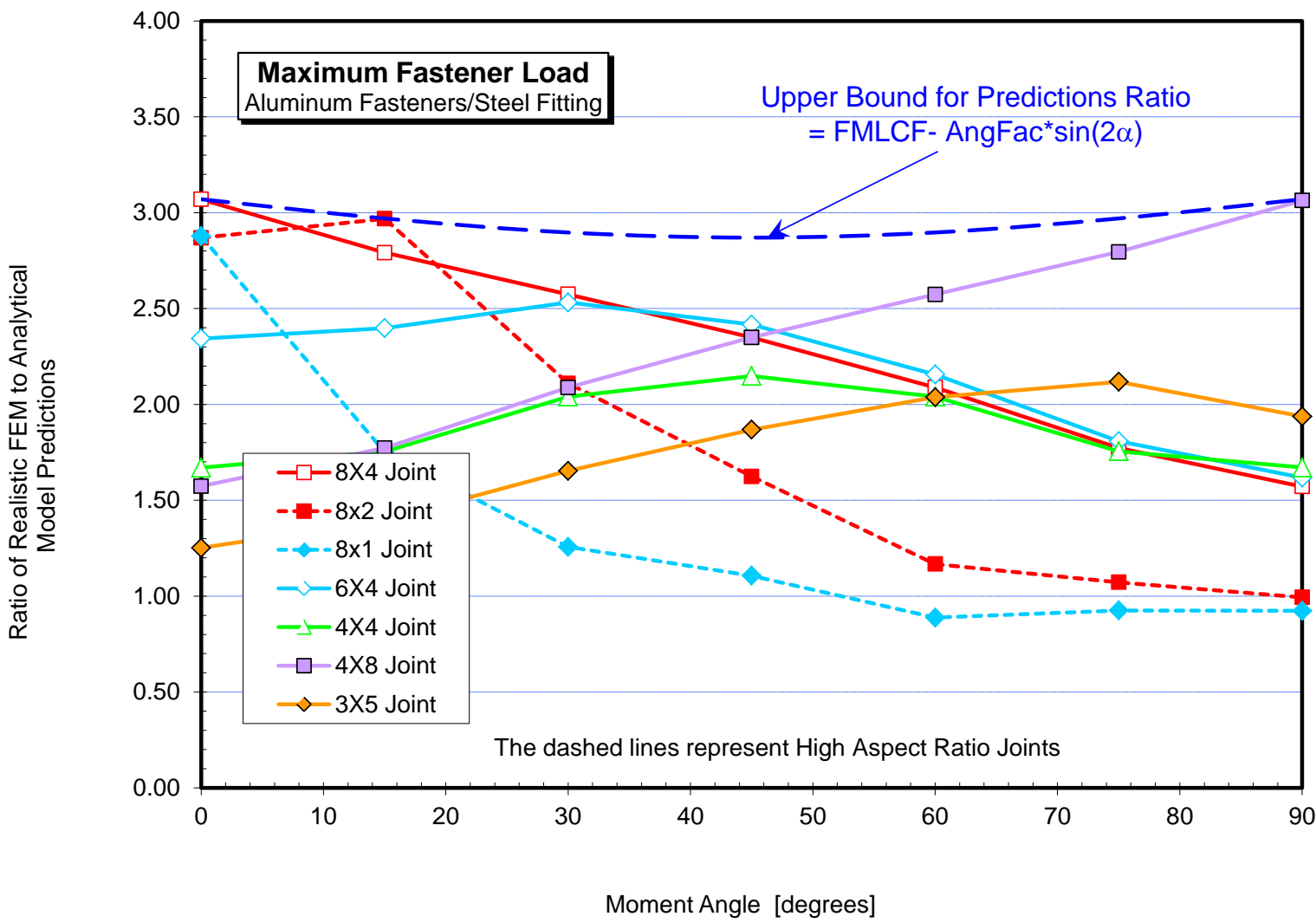

Figure 2: Fastener Maximum Load Correction Factor Plots for Aluminum Fasteners and Steel Fitting 


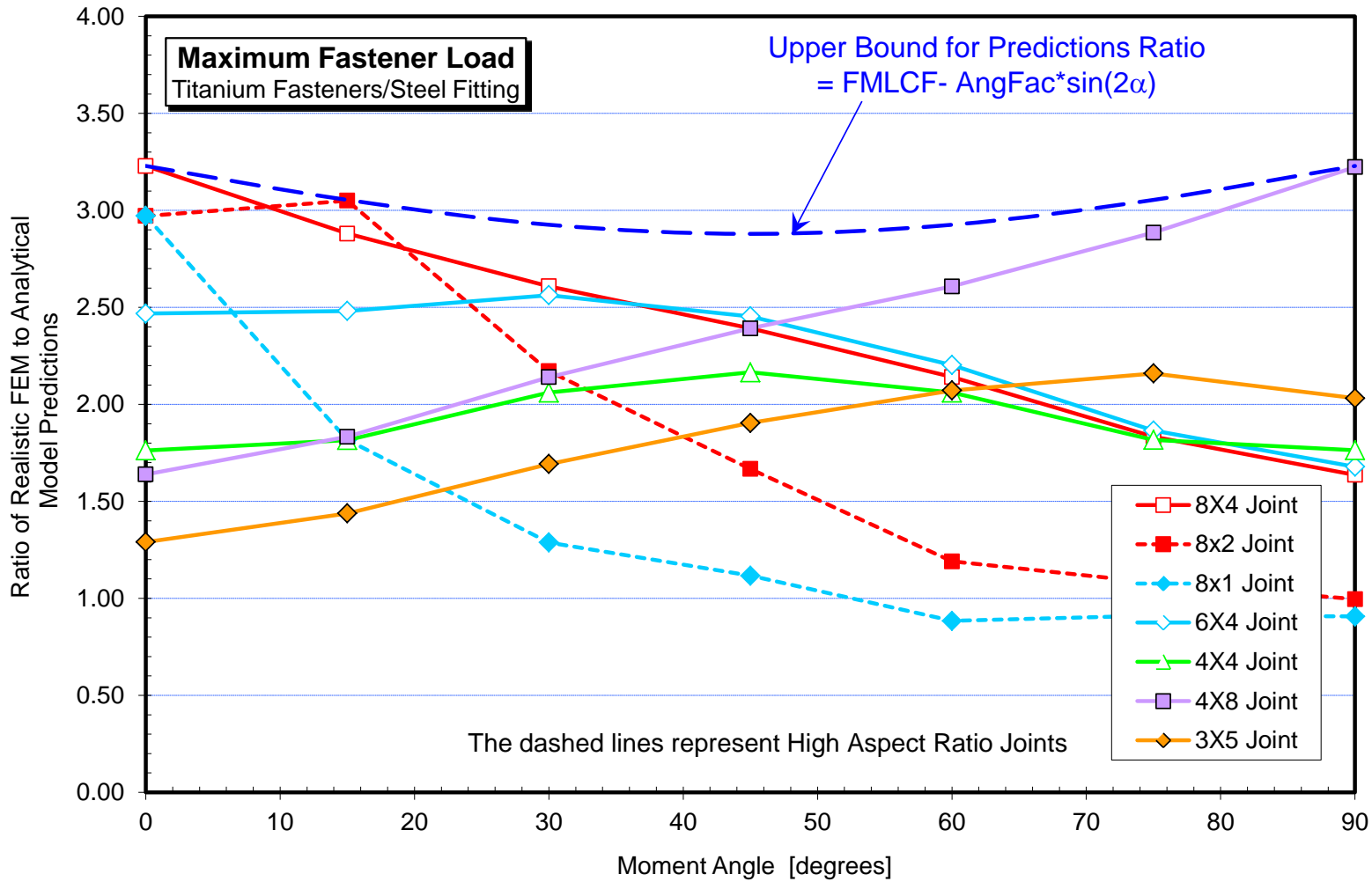

Figure 3: Fastener Maximum Load Correction Factor Plots for Titanium Fasteners and Steel Fitting

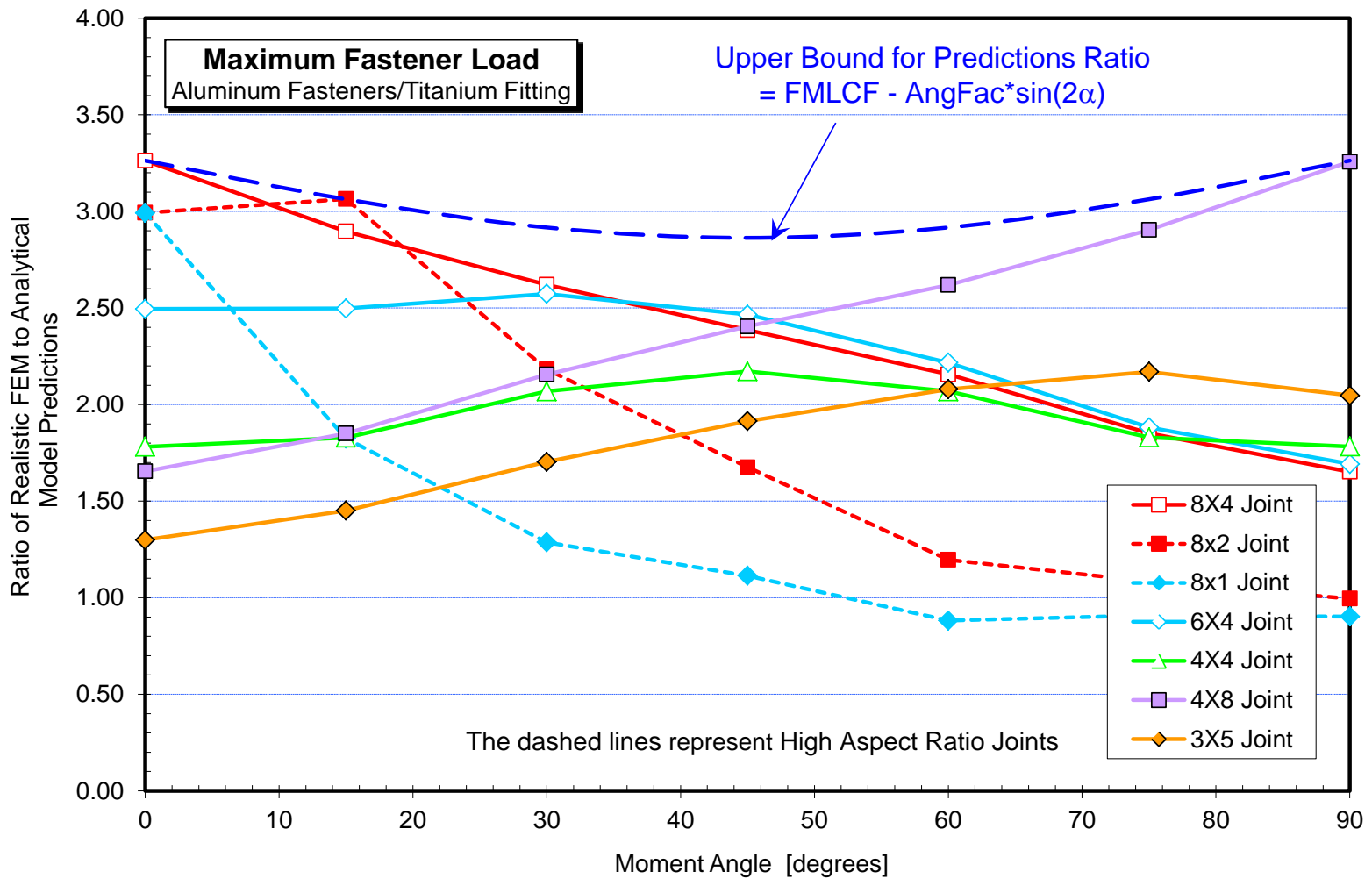

Figure 4: Fastener Maximum Load Correction Factor Plots for Aluminum Fasteners and Titanium Fitting 


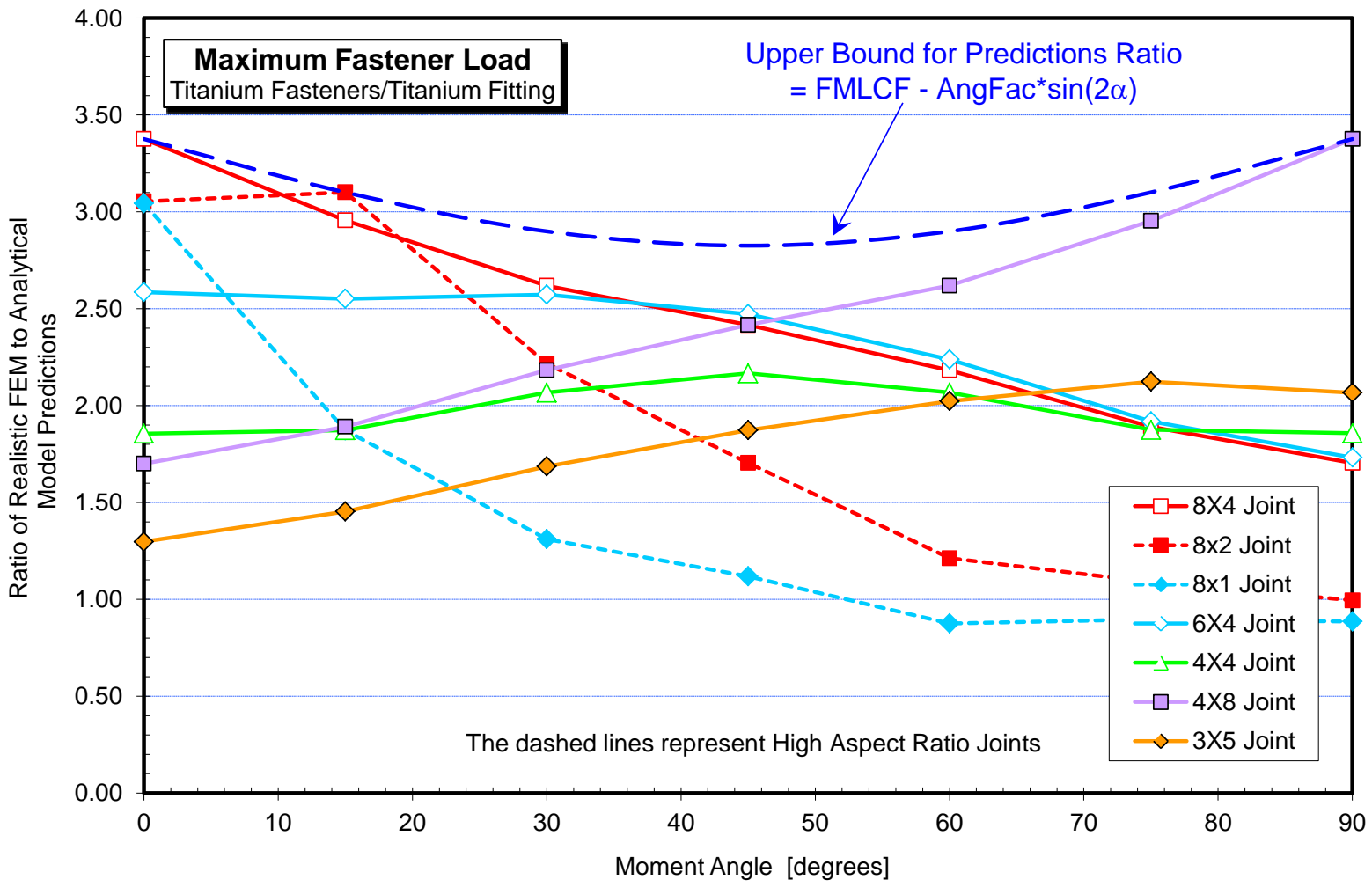

Figure 5: Fastener Maximum Load Correction Factor Plots for Titanium Fasteners and Titanium Fitting

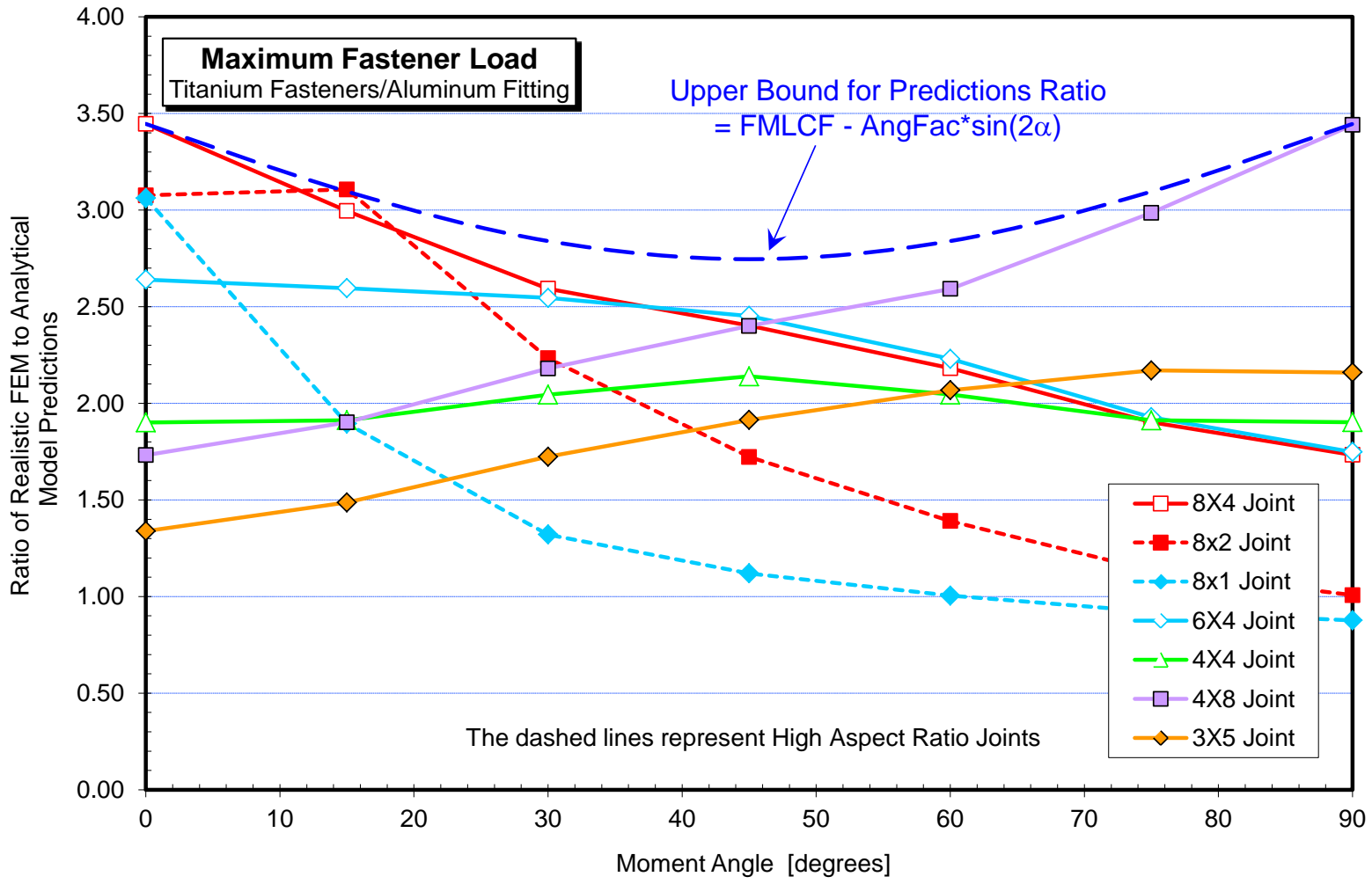

Figure 6: Fastener Maximum Load Correction Factor Plots for Titanium Fasteners and Aluminum Fitting 


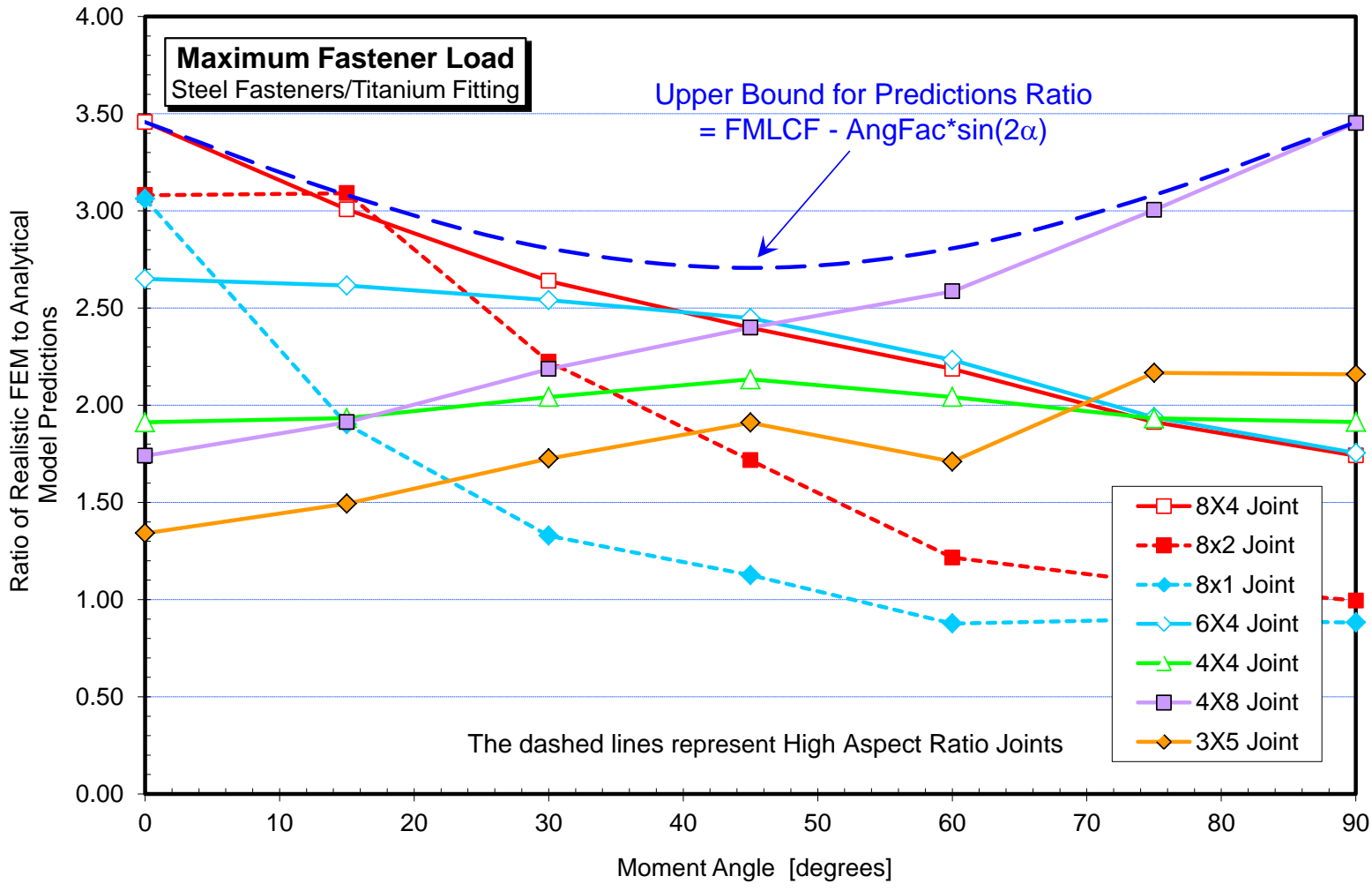

Figure 7: Fastener Maximum Load Correction Factor Plots for Steel Fasteners and Titanium Fitting

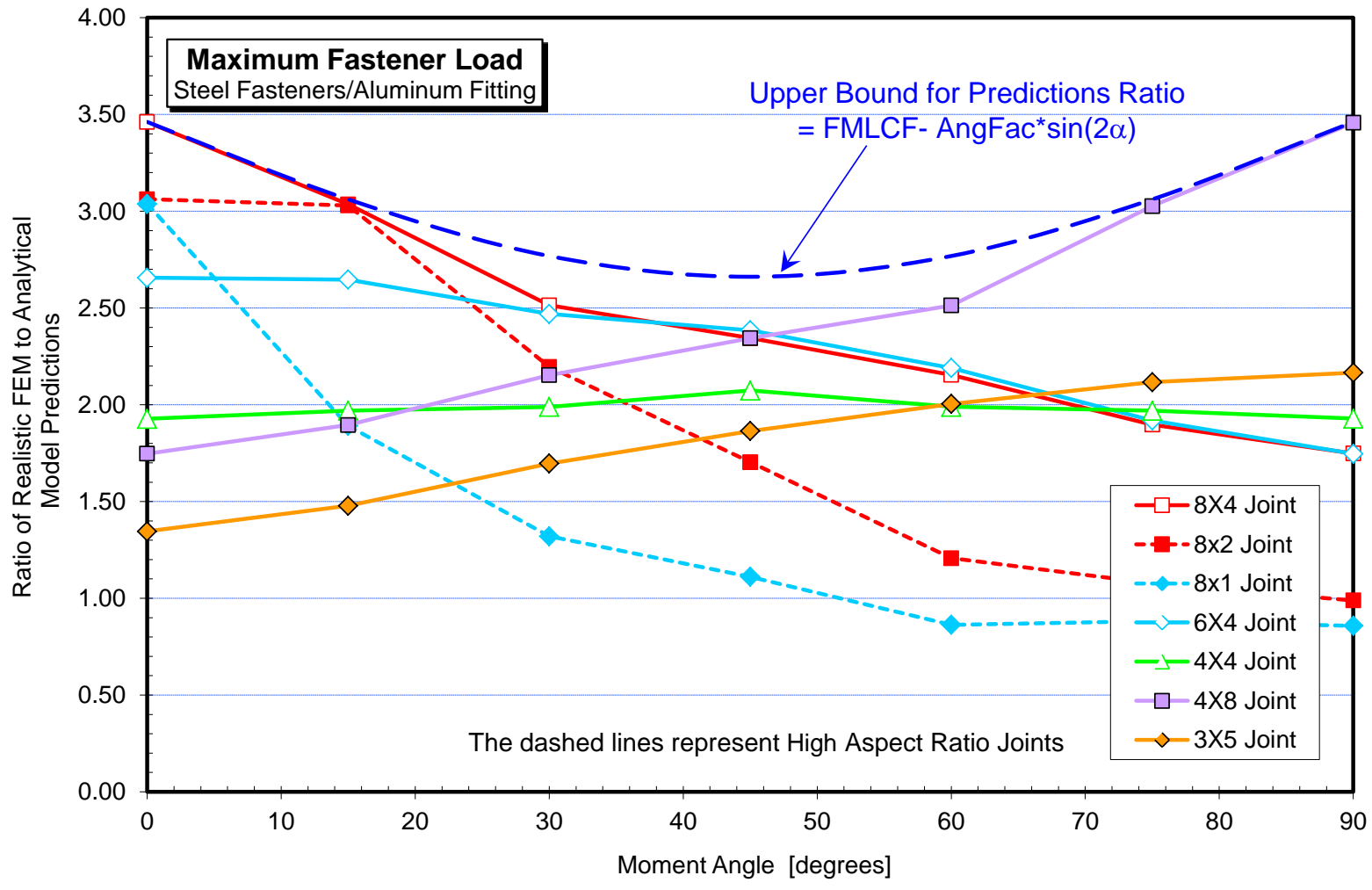

Figure 8: Fastener Maximum Load Correction Factor Plots for Steel Fasteners and Aluminum Fitting 


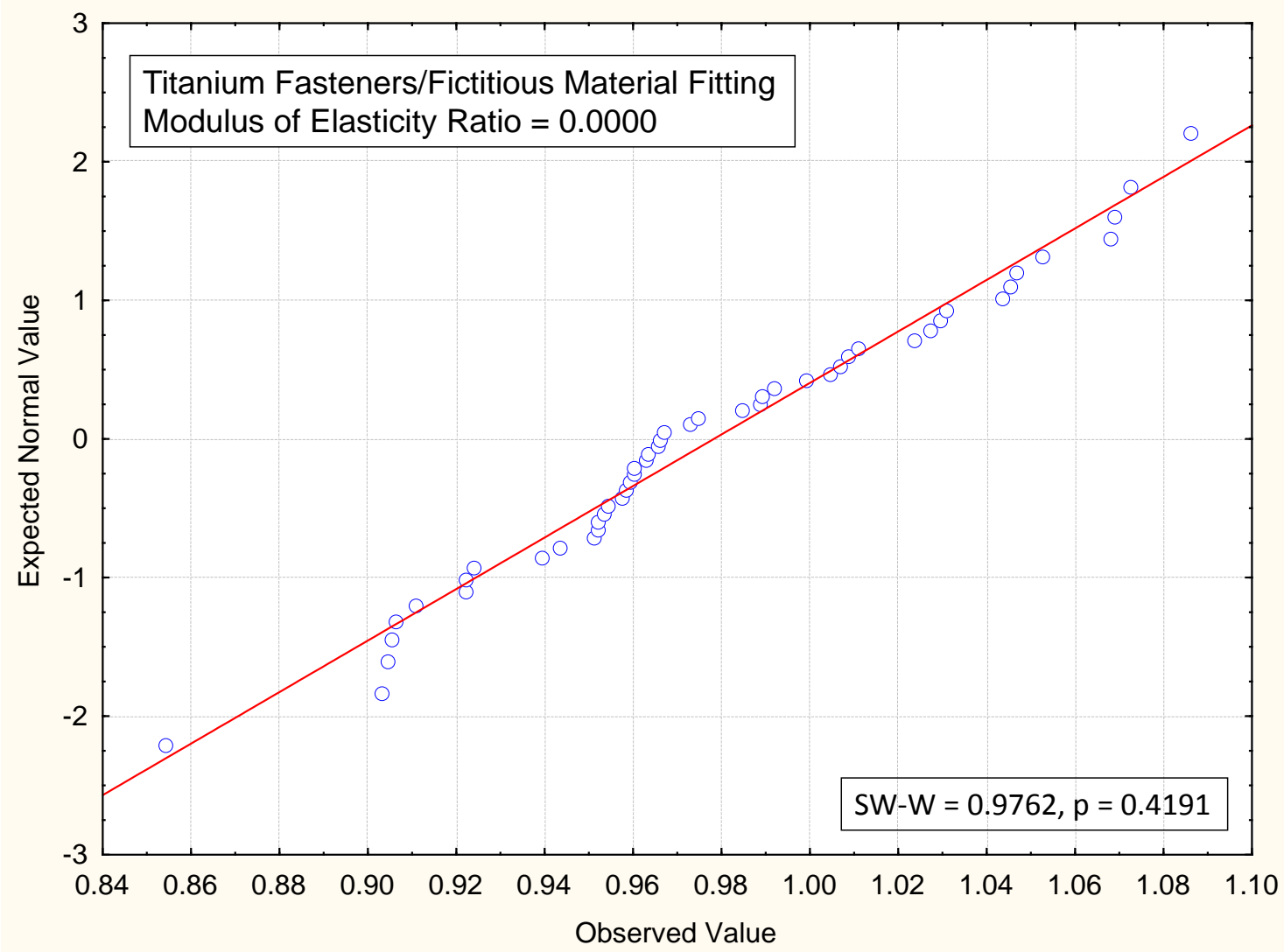

Figure 9: Normal Probability Plot of Fastener Maximum Load Correction Factors for Titanium Fasteners and Fictitious Material Fitting

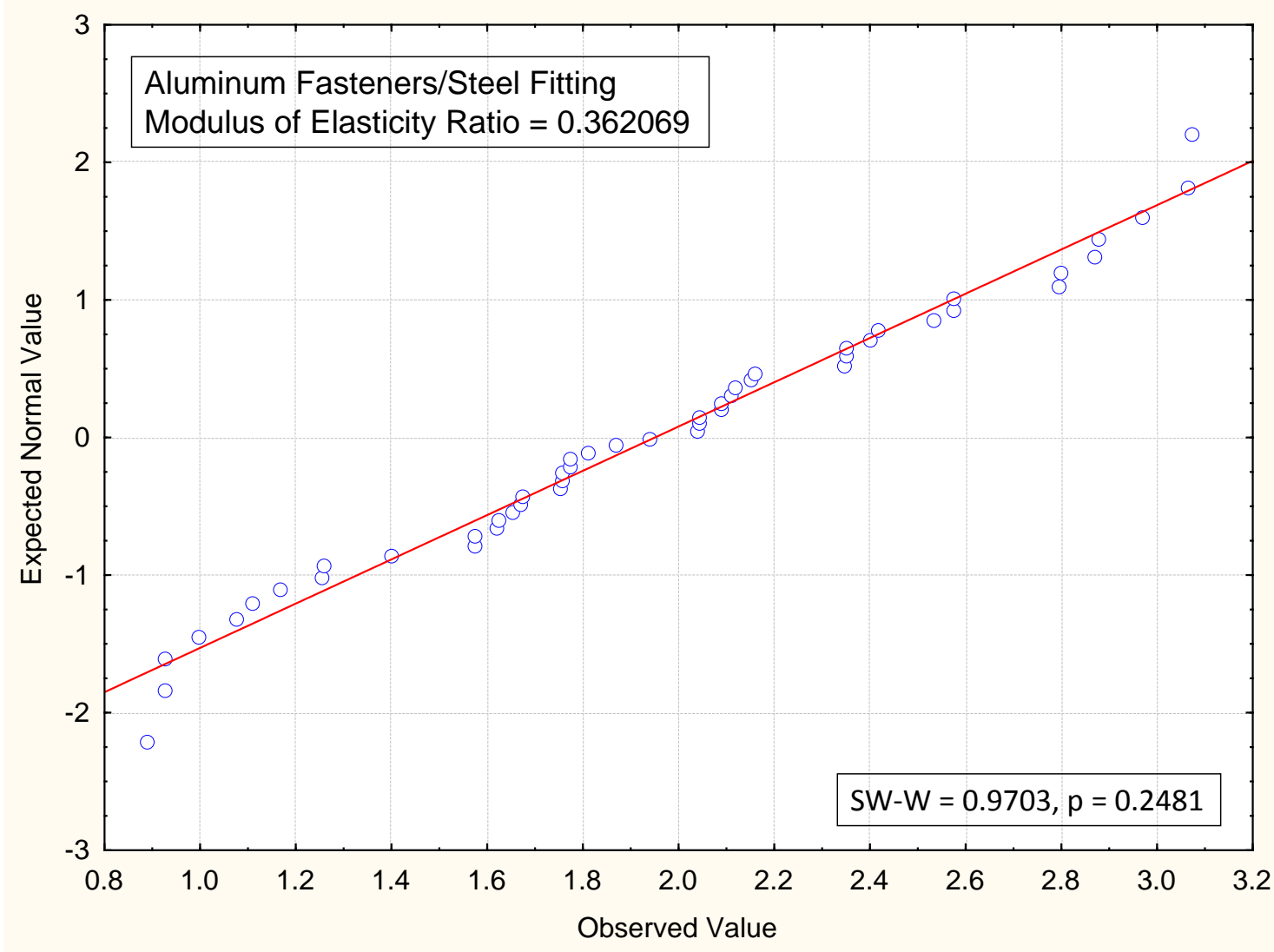

Figure 10: Normal Probability Plot of Fastener Maximum Load Correction Factors for Aluminum Fasteners and Steel Fitting 


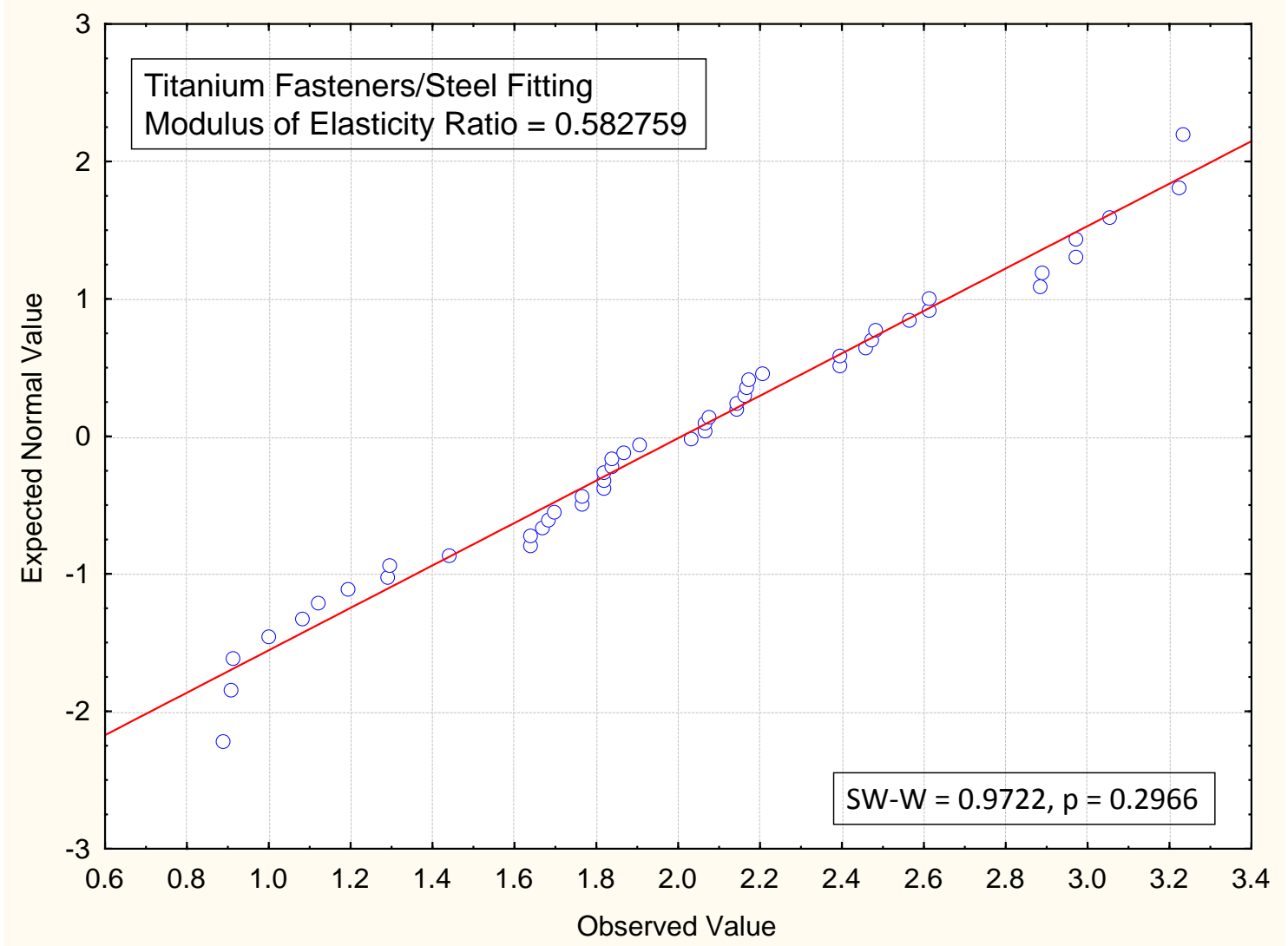

Figure 11: Normal Probability Plot of Fastener Maximum Load Correction Factors for Titanium Fasteners and Steel Fitting

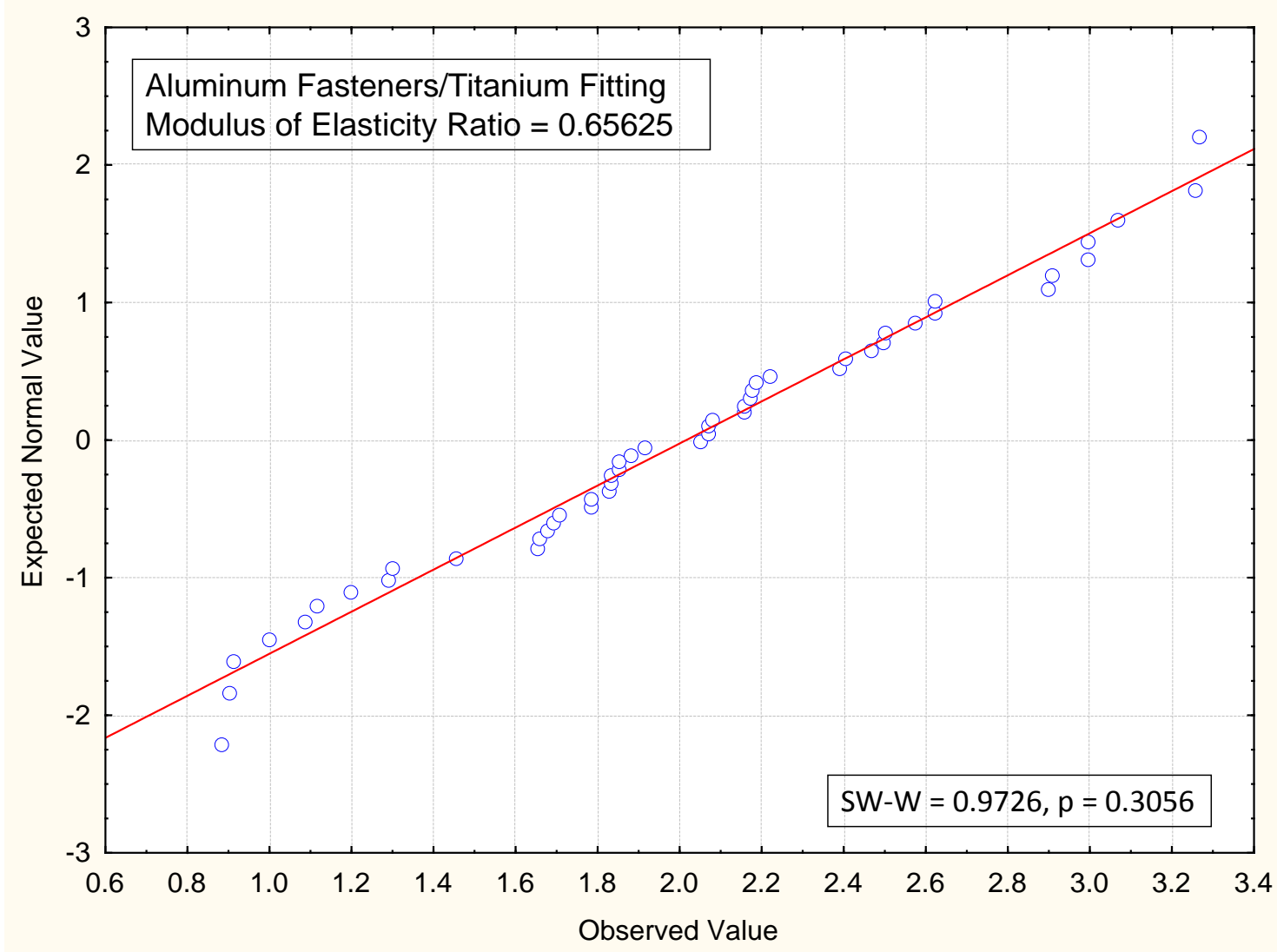

Figure 12: Normal Probability Plot of Fastener Maximum Load Correction Factors for Aluminum Fasteners and Titanium Fitting 


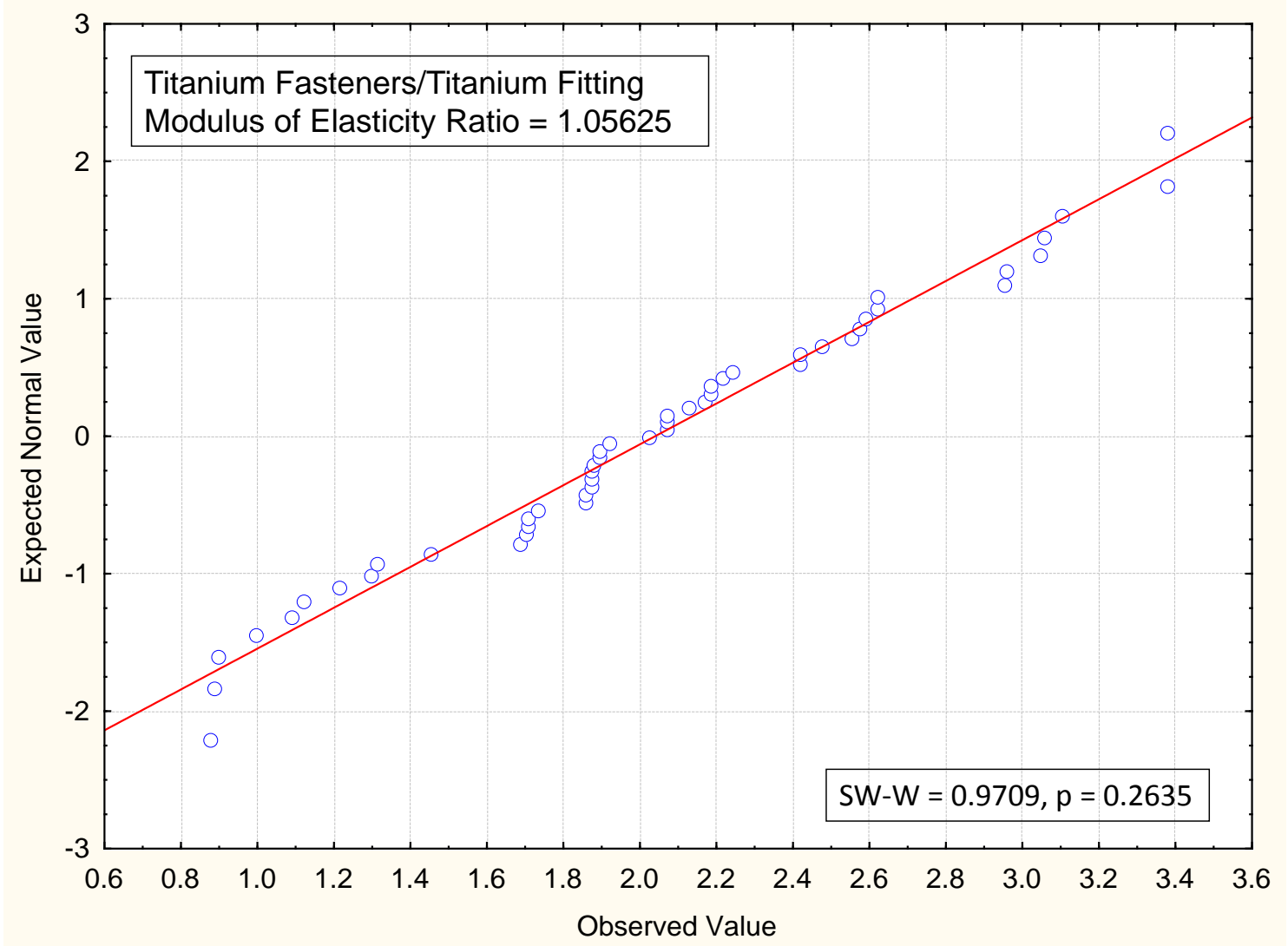

Figure 13: Normal Probability Plot of Fastener Maximum Load Correction Factors for Titanium Fasteners and Titanium Fitting

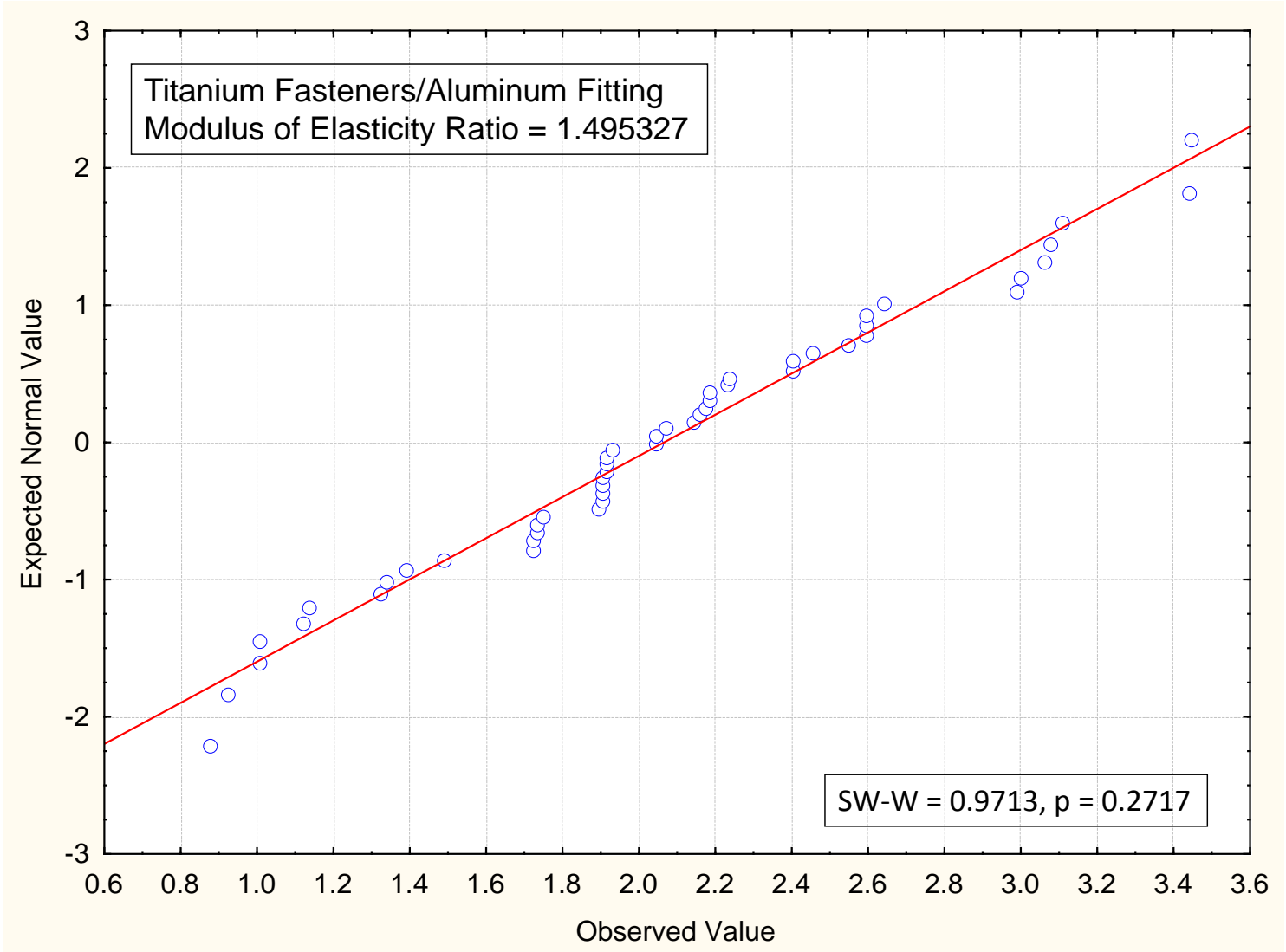

Figure 14: Normal Probability Plot of Fastener Maximum Load Correction Factors for Titanium Fasteners and Aluminum Fitting 


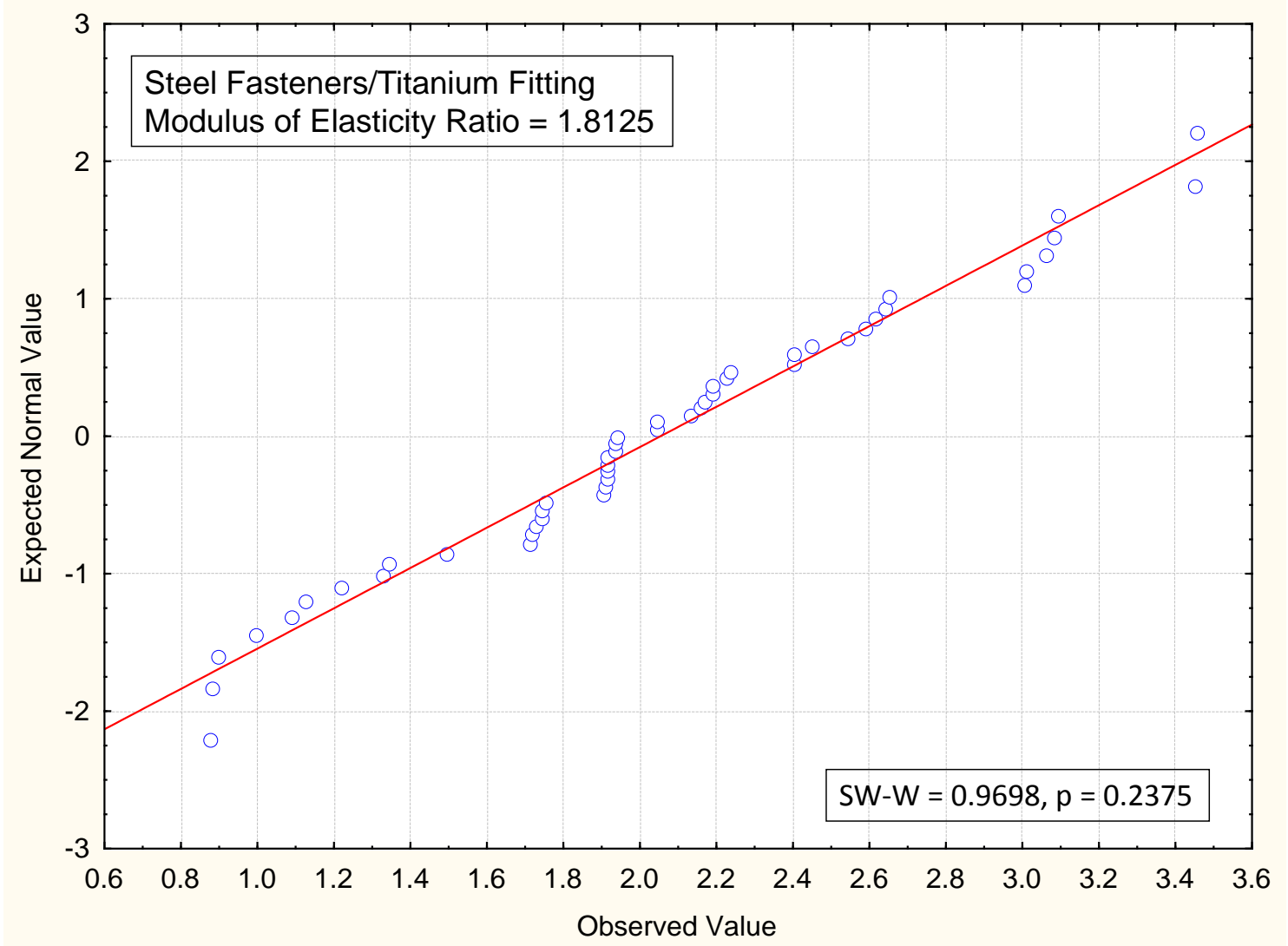

Figure 15: Normal Probability Plot of Fastener Maximum Load Correction Factors for Steel Fasteners and Titanium Fitting

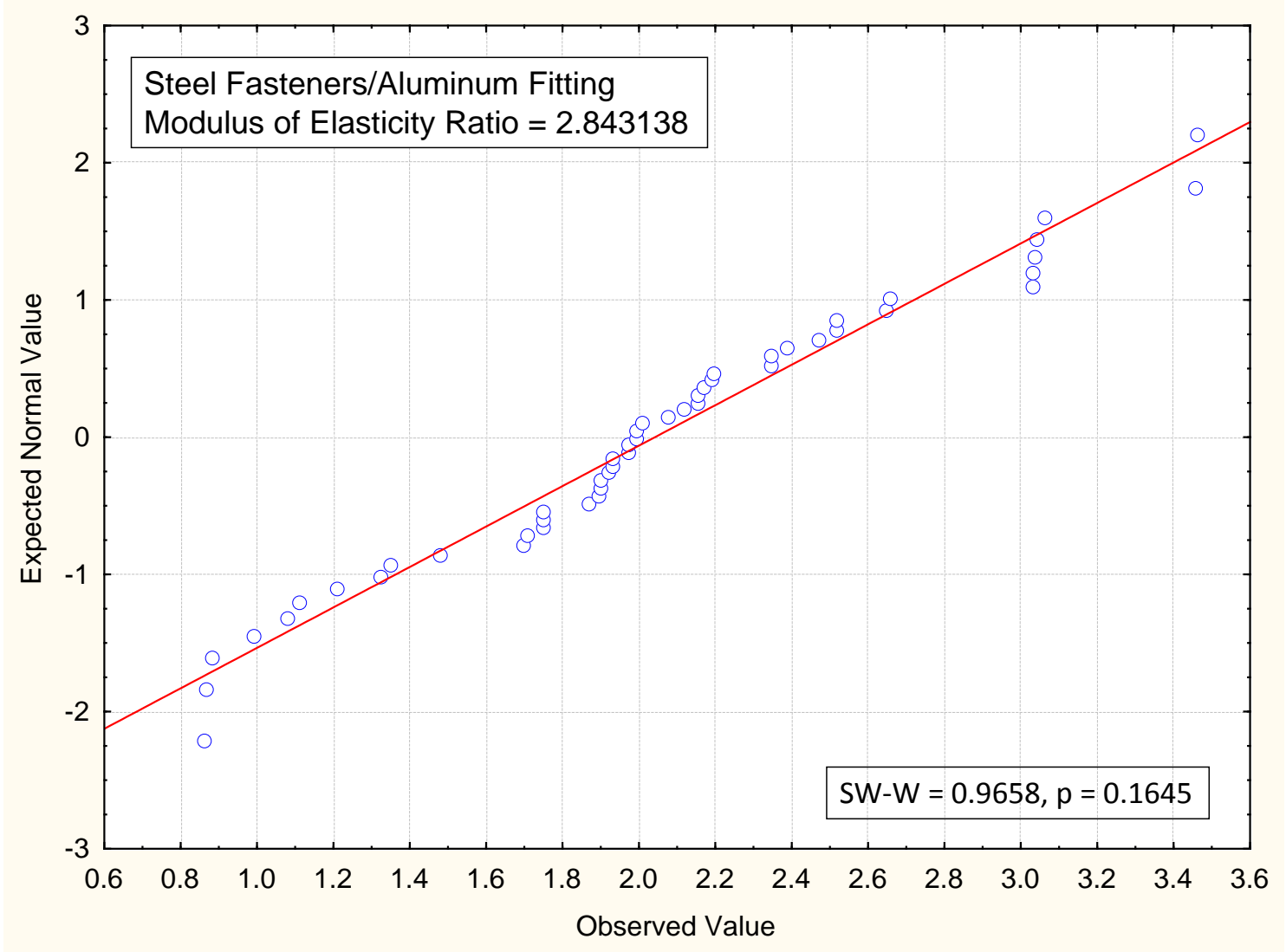

Figure 16: Normal Probability Plot of Fastener Maximum Load Correction Factors for Steel Fasteners and Aluminum Fitting 


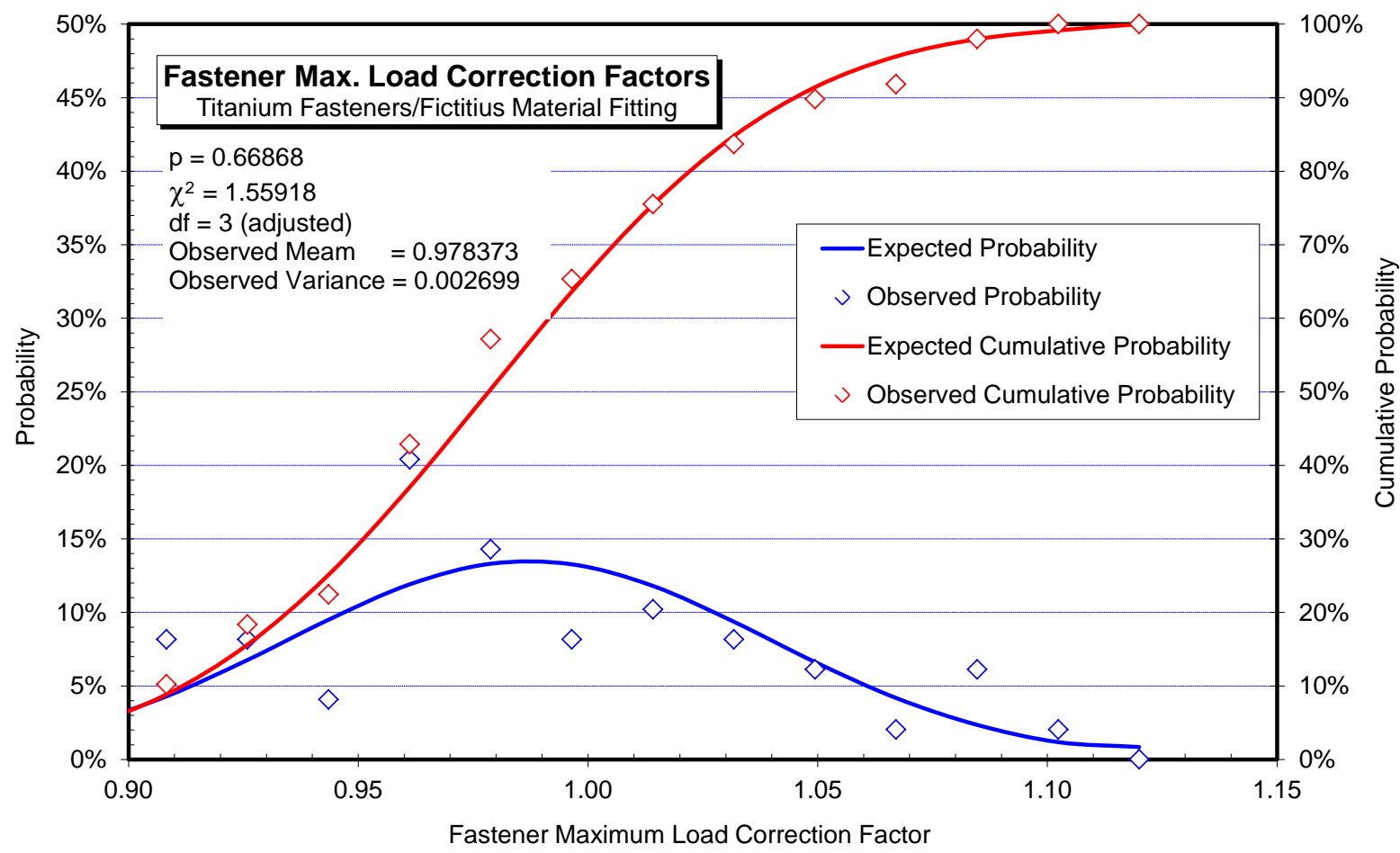

Figure 17: Normal Probability and Cumulative Probability Plots for the Fastener Maximum Load Correction Factors of Titanium Fasteners and Fictitious Material Fitting

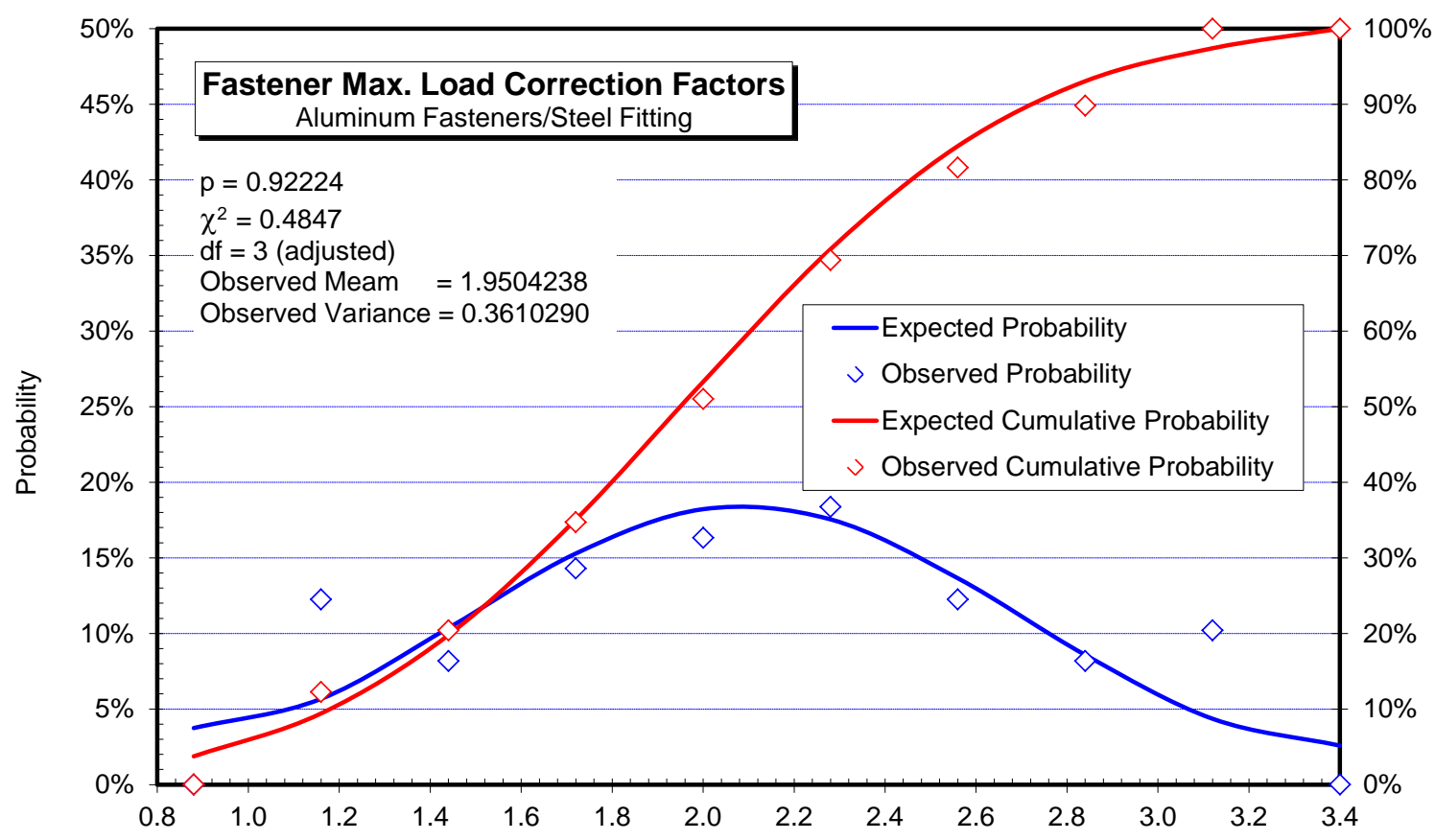

Figure 18: Normal Probability and Cumulative Probability Plots for the Fastener Maximum Load Correction Factors of Aluminum Fasteners and Steel Fitting 


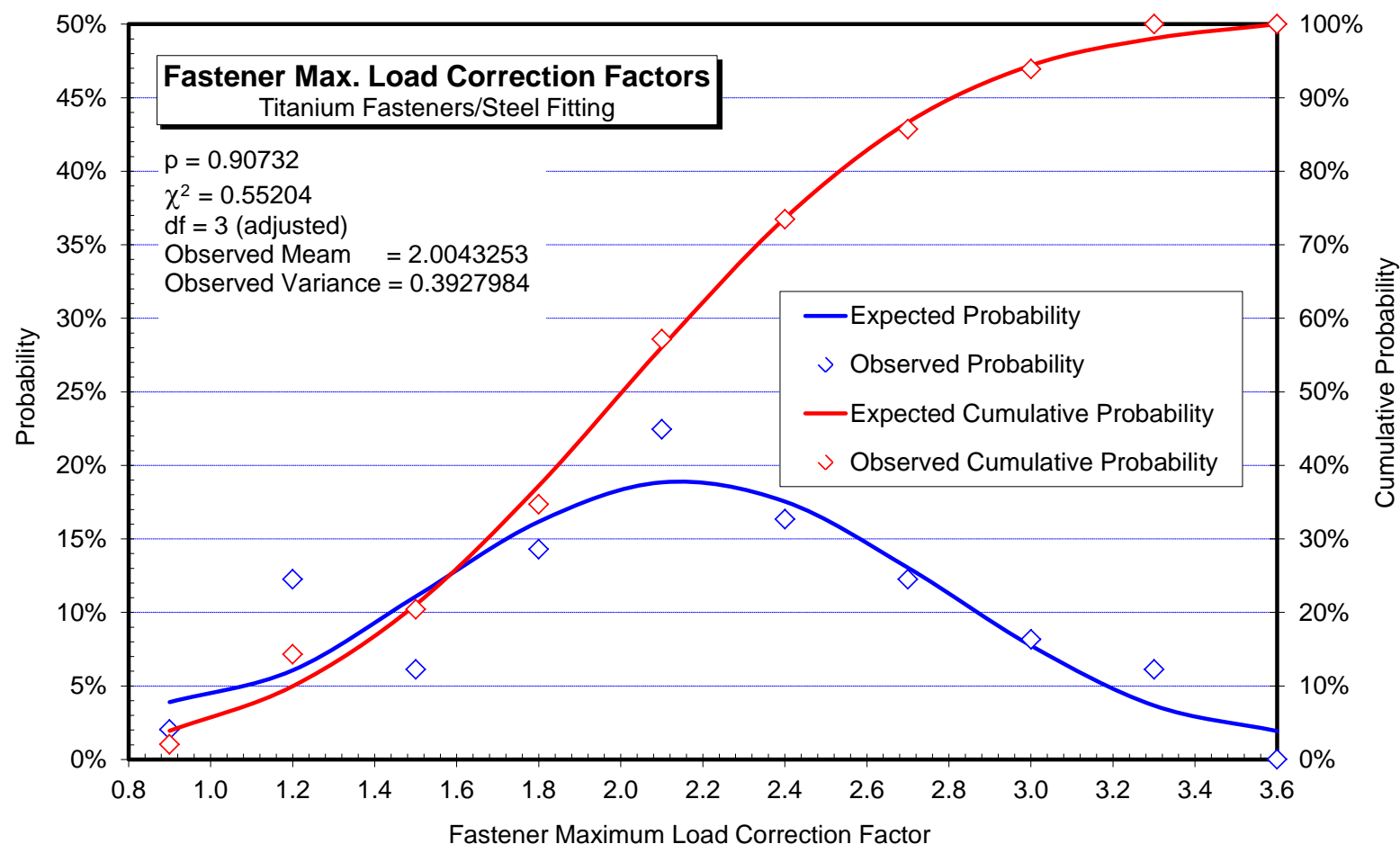

Figure 19: Normal Probability and Cumulative Probability Plots for the Fastener Maximum Load Correction Factors of Titanium Fasteners and Steel Fitting

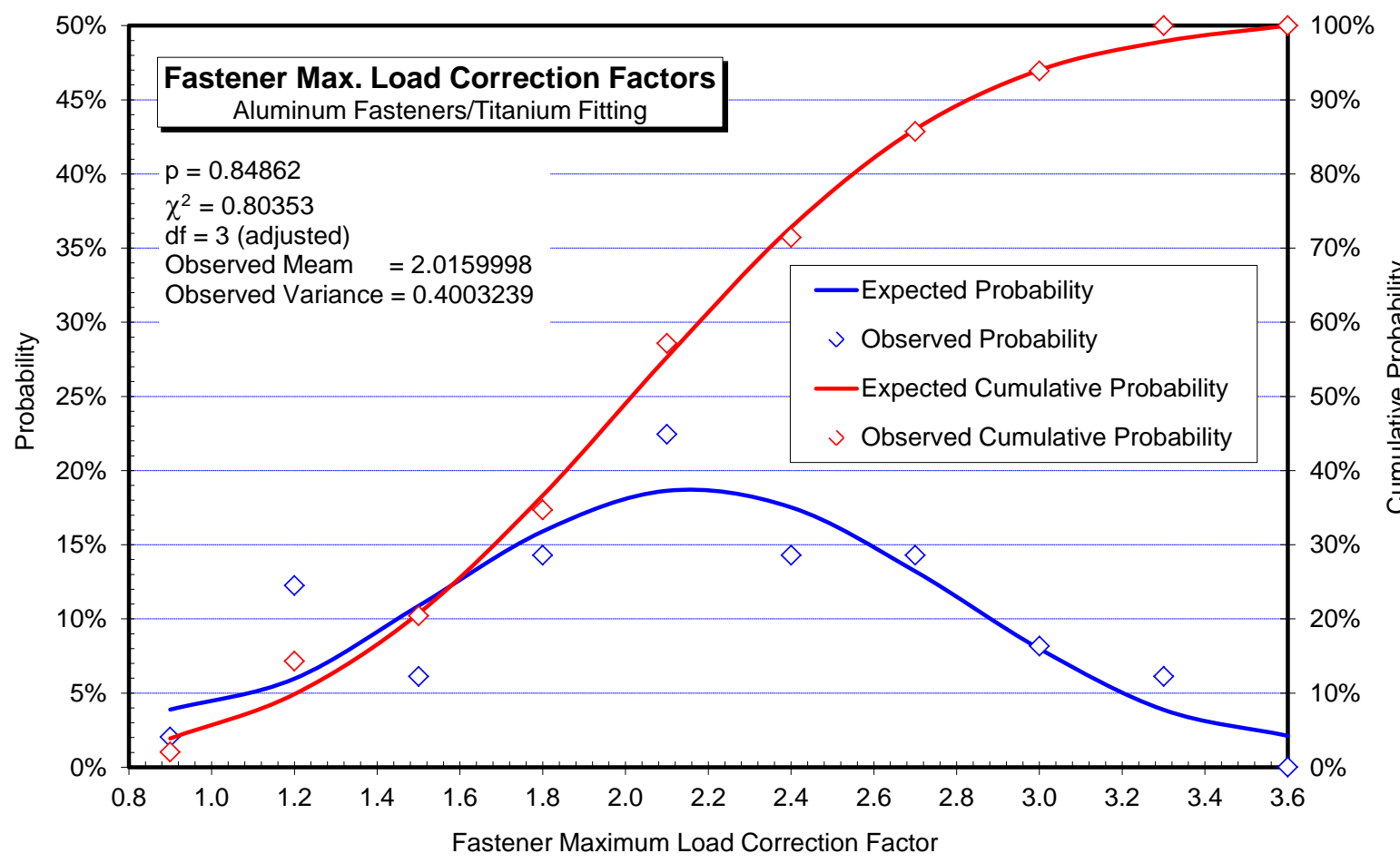

Figure 20: Normal Probability and Cumulative Probability Plots for the Fastener Maximum Load Correction Factors of Aluminum Fasteners and Titanium Fitting 


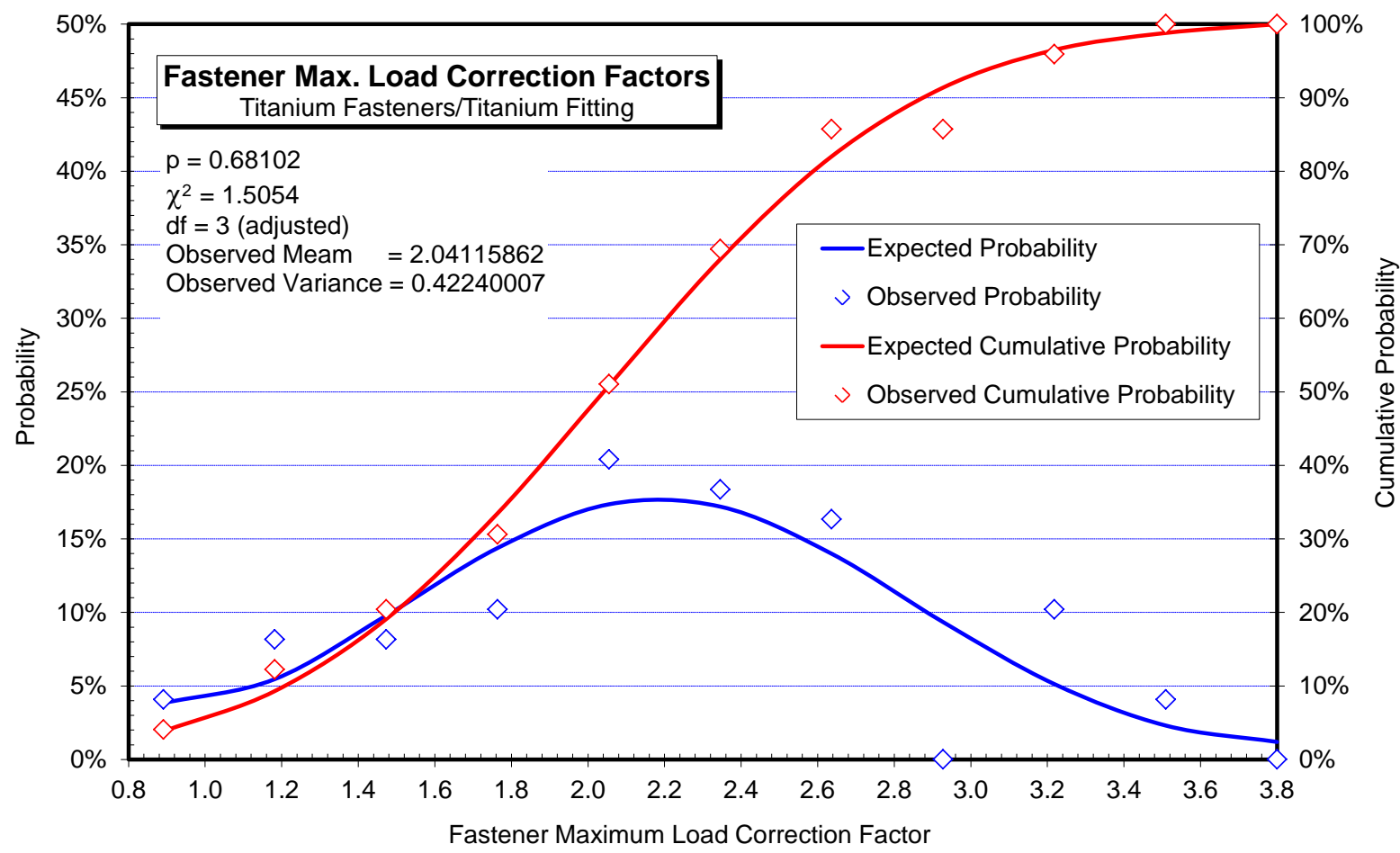

Figure 21: Normal Probability and Cumulative Probability Plots for the Fastener Maximum Load Correction Factors of Titanium Fasteners and Titanium Fitting

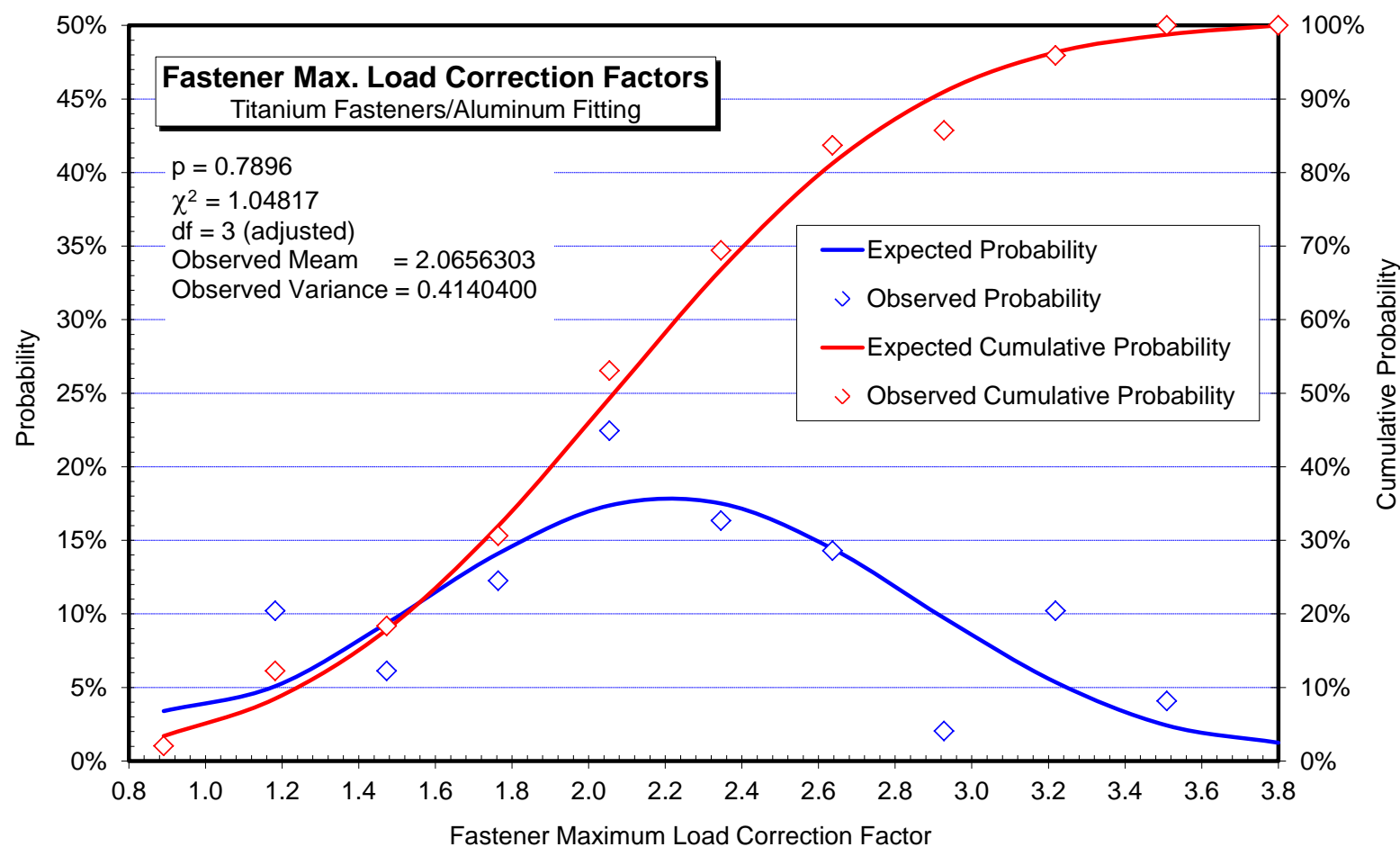

Figure 22: Normal Probability and Cumulative Probability Plots for the Fastener Maximum Load Correction Factors of Titanium Fasteners and Aluminum Fitting 


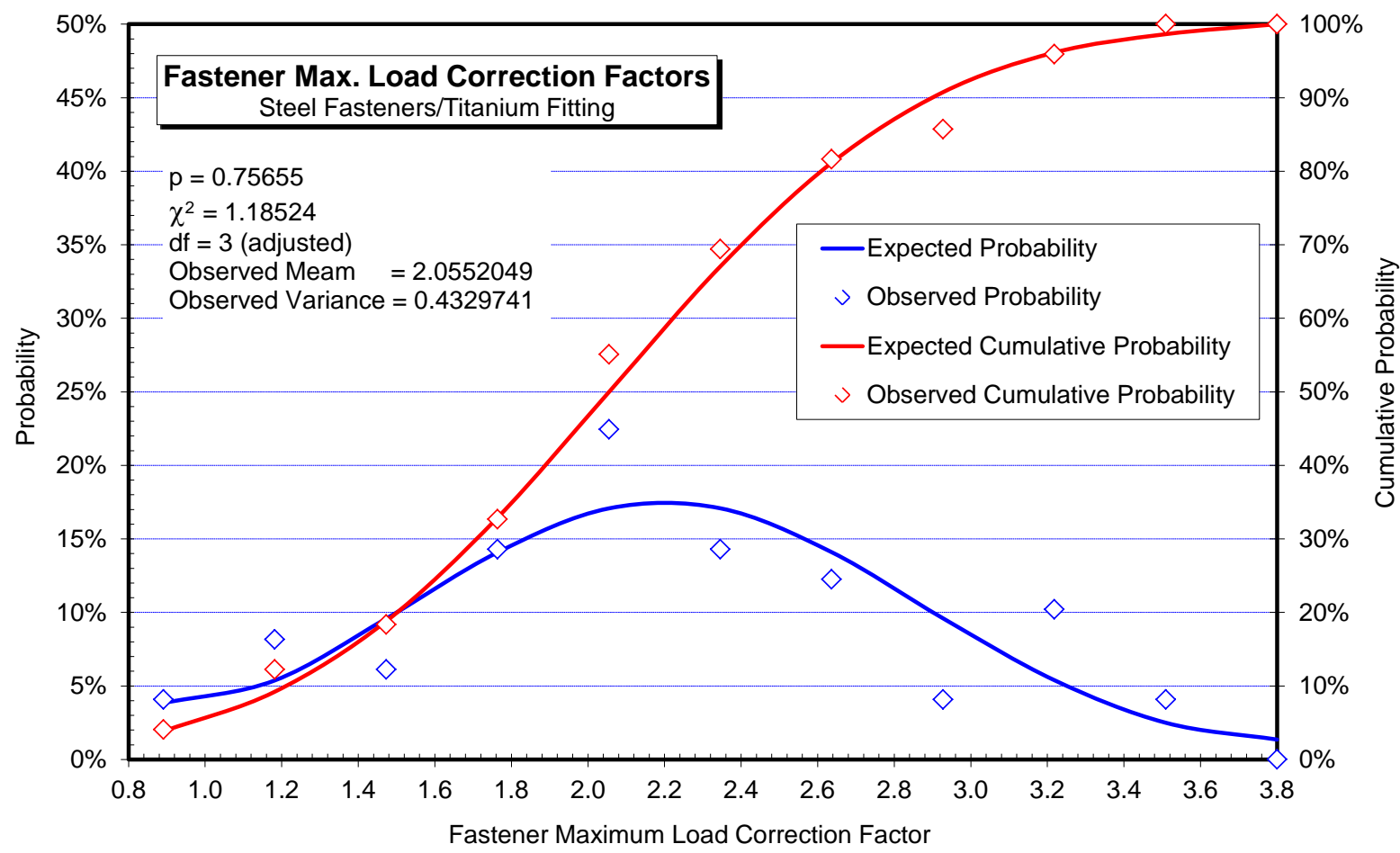

Figure 23: Normal Probability and Cumulative Probability Plots for the Fastener Maximum Load Correction Factors of Steel Fasteners and Titanium Fitting

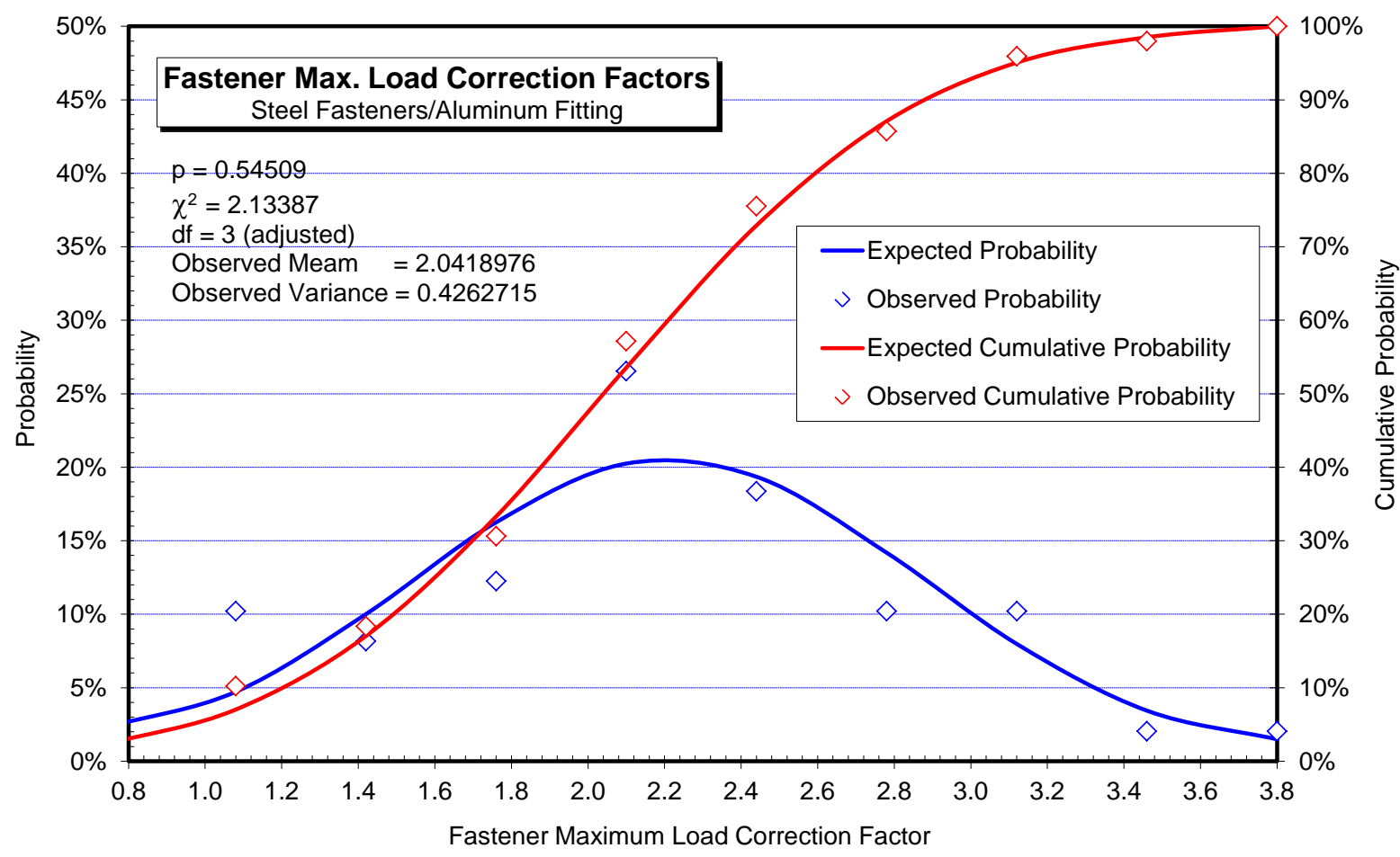

Figure 24: Normal Probability and Cumulative Probability Plots for the Fastener Maximum Load Correction Factors of Aluminum Fasteners and Steel Fitting 


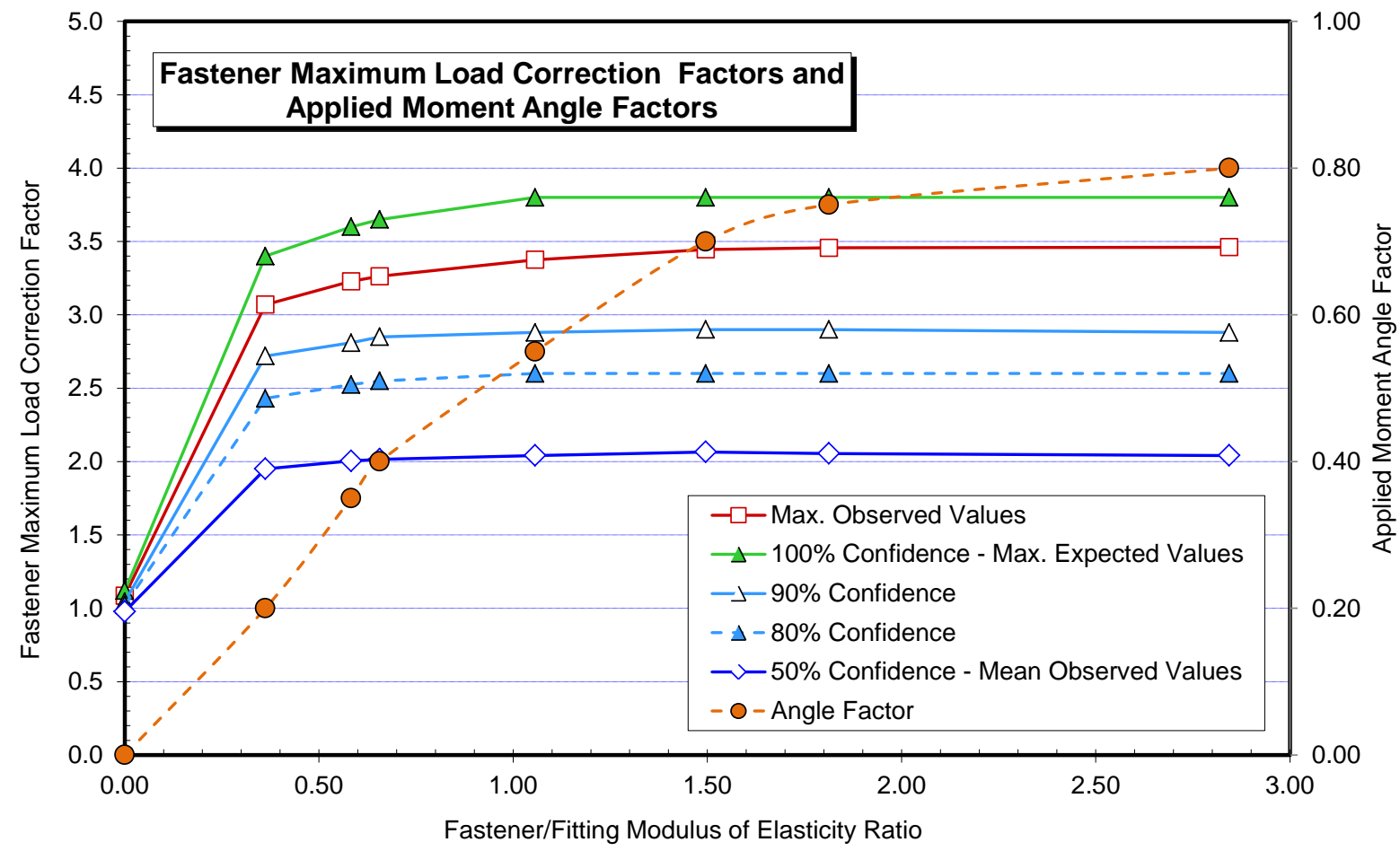

Figure 25: Fastener Maximum Load Correction Factors and Angle Factors versus the Fasteners/Fitting Modulus of Elasticity Ration 